ISSN (print): 1698-6180. ISSN (online): 1886-7995

www.ucm.es/info/estratig/journal.htm

Journal of Iberian Geology 36 (2) 2010: 123-143

doi:10.5209/rev_JIGE.2010.v36.n2.2

\title{
The phylogenetic position of Nyctiphruretus acudens, a parareptile from the Permian of Russia
}

\author{
Posición filogenética de Nyctiphruretus acudens, un parareptil \\ del Pérmico de Rusia
}

\author{
L. K. SäiIä1,2 \\ ${ }^{I}$ Department of Earth Sciences, University of Bristol, Wills Memorial Building, Queen's Road, Bristol, \\ BS8 1JU, United Kingdom \\ ${ }^{2}$ Department of Geosciences and Geography, P.O. Box 64, Gustaf Hällströmin katu 2a, \\ 00014 University of Helsinki, Finland (current affiliation). \\ Laura.Saila@helsinki.fi
}

Received: 09/11/09 / Accepted: 30/12/10

\begin{abstract}
Several specimens preserving the cranial structure of Nyctiphruretus acudens, a parareptile from the Permian Mezen River locality, Russia, are described here for the first time. Previous studies have offered conflicting reconstructed images of Nyctiphruretus but no illustrations of actual specimens. The new information was incorporated into two existing analyses of parareptilian relationships. The results indicate that Nyctiphruretus is closely related to procolophonoids, pareiasaurs and other non-pareiasaurian Mezen River parareptiles but the interrelationships within this group remain unresolved. Nyctiphruretus was recovered either as the sister taxon of a clade formed of pareiasaurs and the other non-pareiasaurian Mezen River parareptiles, or as the sister taxon of procolophonoids. This is the first time the Nyctiphruretus-Procolophonoidea clade received support in a phylogenetic analysis. The interrelationships between several other groups within the Parareptilia also remain unresolved, or poorly supported, highlighting the need for more detailed descriptions and analyses of this enigmatic group of extinct reptiles.
\end{abstract}

Keywords: Parareptilia, Procolophonoidea, Nyctiphruretus acudens, phylogeny, Permian, Russia.

\section{Resumen}

Se describen por primera vez varios ejemplares de Nyctiphruretus acudens que han conservado su estructura craneal, un parareptil del Pérmico de la localidad de Mezen River en Rusia. En estudios previos se documentaron imágenes conflictivas de Nyctiphruretus aunque nunca se publicaron ilustraciones del material fósil. La nueva información se ha incorporado a dos análisis ya publicados de las relaciones de parentesco de parareptiles. Los resultados indican que de Nyctiphruretus está próximamente emparentado con procolofónidos, pareiasaurios y otros parareptiles no-pareiasaurios de Mezen River, aunque las interrelaciones dentro de este grupo quedan sin resolver. Nyctiphruretus aparece como el grupo hermano de un clado formado por pareiasaurios y los demás parareptiles 
no-pareisaurios de Mezen River, o bien como el grupo hermano de procolofónidos. Es el primer resultado que el clado Nyctiphruretus-Procolophonoidea queda diagnosticado en un análisis filogenético. Las interrelaciones en otros varios grupos de Parareptilia también permanecen sin resolver, o bien quedan pobremente soportadas, resaltándose la necesidad de realizar descripciones más detalladas y análisis de este grupo tan enigmático de reptiles extintos.

Palabras clave: Parareptilia, Procolophonoidea, Nyctiphruretus acudens, filogenia, Pérmico, Rusia.

\section{Introduction}

The Procolophonoidea is an important group of smallto medium-sized parareptiles that emerged in the Permian and had a global distribution before disappearing by the end of the Triassic period. In recent years, several new, and old, genera and species have been described in detail (Gow, 2000; Cisneros and Schultz, 2003; Modesto and Damiani, 2003, 2007; Modesto et al., 2001; Novikov and Sues, 2004; Piñeiro et al., 2004; Cisneros 2008a, b; Säilä 2008). Procolophonoids have also become the focus of broader interest because they been proposed to be the sister group of turtles (Laurin and Reisz, 1995; Reisz and Laurin, 1991) and it has also been estimated that up to $80 \%$ of procolophonoid lineages survived the Permian-Triassic $(\mathrm{P} / \mathrm{Tr})$ extinction event (Ketchum and Barrett, 2004; Modesto et al., 2001, 2003), which killed up to 95\% of all species on Earth (Benton and Twitchett, 2003). However, the survival rate for Procolophonoidea strongly depends on the number and affinities of Permian procolophonoids, both of which have remained poorly known especially for the Laurasian members of the group.

European Russia is the only place outside southern Africa where a succession of procolophonoids from the Permian and the Triassic are found, but the Permian Russian procolophonoids have been very poorly known, and their procolophonoid affinities thus remained uncertain (Spencer and Benton, 2000; Bulanov, 2002; Cisneros, 2008c). Most phylogenetic studies agree that the Procolophonoidea can be divided into two families, Owenettidae and Procolophonidae (Cisneros, 2008b, c; deBraga, 2003; Modesto and Damiani, 2007; Säilä 2008) and a Permian origin for the Procolophonidae has been based on Microphon exiguuus, Ivakhnenko, 1983 from the Upper Permian of Russia (Spencer and Benton, 2000; Modesto et al., 2001; Benton et al. 2004). Bulanov $(2002,2003)$, however, subsequently excluded Microphon from Procolophonoidea after reidentifying it as a seymouriamorph, and this was confirmed by Säilä (2009) who was the first to illustrate the damaged holotype of M. exiguuus with photographs and pointed out its supposed procolophoid features to be either damaged or wrongly identified structures.
In addition to Microphon, other Permian fossils collected from Russia have been assigned to Procolophonidae. Bulanov (2002) considered the taxa Nyctiphruretus, Suchonosaurus and Kinelia from the Upper Permian of Russia as 'procolophons' (sensu the terminology of Bulanov, 2002). Cisneros (2008c) went on to exclude Suchonosaurus from Procolophonoidea based on its 'pleurodont dentition', interpreted as such from the original descriptive drawings of Tverdokhlebova and Ivakhnenko (1994), but a review by Säilä (2009) illustrates that the dentition is instead protothecodont and Suchonosaurus can be assigned to the procolophonoid clade Procolophonidae. In the same review of the putative Permian procolophonoid taxa known from only fragmentary remains, Säilä (2009) excludes Kinelia from Procolophonoidea, and reclassifies it as a tetrapod incertae sedis.

In addition to these, a fourth taxon, Nyctiphruretus acudens Efremov 1938, a parareptile found in the Mezen River basin of Russia, Upper Permian (Guadalupian) (Ivakhnenko 1990), has been considered a member of the Order Procolophonomorpha, Family Nyctiphruretidae and understood to be the most basal of the Russian 'procolophons' (Bulanov, 2002; Ivakhnenko, 1979, 1987, 1990; Tverdokhlebova and Ivakhnenko, 1994). The phylogenetic analyses of Lee (1995), Tsuji (2006) and Müller and Tsuji (2007), however, do not support the view of Nyctiphruretus as a basal 'procolophon' and instead recognise Nyctiphruretus as a non-procolophonoid parareptile, possibly more closely related to pareiasaurs than procolophonoids (Tsuji, 2006). However, Tsuji (2006) points out that the published reconstructions of Nyctiphruretus (Chudinov, 1957; Efremov, 1940; Ivakhnenko, 1979; Lee, 1995, 1997) differ from each other markedly, and an in-depth study of this taxon is needed to resolve its phylogenetic position.

There are currently over one hundred specimen of $\mathrm{Nycti-}$ phruretus acudens housed at PIN (Bulanov 2002), yet the osteology and affinities of Nyctiphruretus remain poorly known. Both Ivakhnenko (1979) and Lee (1995, 1997), and more recently also Müller and Tsuji (2007), present only reconstructions of the skull but no illustrations of the actual specimens. In order to resolve the phylogenetic affinities of Nyctiphruretus, and its possible procolophonoid status, some of the best-preserved cranial specimens 
are illustrated and briefly described here and the resulting new information is incorporated into two published data matrices (Tsuji, 2006; Müller and Tsuji, 2007) for a reanalysis of parareptilian relationships. The postcranial anatomy of Nyctiphruretus is not described in this paper but Bulanov (pers. comm.) is currently conducting a more comprehensive study on the osteology and ontogeny of Nyctiphruretus.

Institutional abbreviations. BMNH, Natural History Museum, London;

PIN, Paleontological Institute, Russian Academy of Sciences, Moscow; SAM, Iziko: South African Museum, Cape Town.

Anatomical abbreviations. a, angular; art, articular; bo, basioccipital; d, dentary; ect, ectopterygoid; f, frontal; $\mathbf{j}$, jugal; l, lacrimal; mcg, meckelian groove; mx, maxilla; n, nasal; op, opisthotic; p, parietal; pal, palatine; pf, postfrontal; pmx, premaxilla; po, postorbital; pp, postparietal; pro, prootic; prf, prefrontal; pbs, parabasisphenoid; pt, pterygoid; q, quadrate, qj, quadratojugal; so, supraoccipital; sp, splenial; sq, squamosal; st, supratemporal; sa, surangular; ta, tabular; v, vomer

\section{Materials and methods}

Nyctiphruretus is represented by two species, Nyctiphruretus acudens and N. optabilis Bulanov (2002). Nyctiphruretus optabilis is known from only one fragmented dentary (Bulanov, 2002), whereas N. acudens is represented by numerous cranial and postcranial specimens. The only difference between the species is a slightly different dentition (Bulanov, 2002), and for this reason, $N$. acudens is the species of Nyctiphruretus discussed here and is from now on referred to simply as Nyctiphruretus.

The Nyctiphruretus specimens illustrated and discussed in this study are:

PIN 4659/1, the best-preserved skull, revealing many details of dorsal skull and palate, no mandible attached (Figs. 1, 2).

PIN 158/4, well-preserved skull (Figs 3A). This specimen also has a well-preserved, nearly complete postcranial skeleton, which is not described here.

PIN 158/5, crania with good preservation of posterior border of dorsal skull (Fig. 3B), right mandibular ramus and some braincase elements (Fig. 6A).

PIN 4660/18, skull with well-preserved temporal region; both mandibular rami present (Fig. 4).

PIN 158/6, partial skull; fairly well-preserved left mandibular ramus (Fig. 5B).

PIN 162/1, skull with a well-preserved braincase and palate in ventral view (Fig. 6B).
PIN 158/7, moderately preserved skull with good preservation of the temporal area (Fig. 5A)

The cranial characters for the phylogenetic analysis were checked against the illustrated specimens, the postcranial characters of the Müller and Tsuji (2007) analysis against the well-preserved postcrania of PIN 158/4 and PIN 162, and the braincase characters against the descriptions of Ivakhnenko (1979) for the elements that were not preserved in the cranial material studied for this analysis.

\section{Description}

\subsection{Dorsal skull}

The skull is almost triangular in dorsal view, and has very large orbital openings (Figs 1A, 2A). The dorsal surface of the skull is covered with dermal tuberosities but the jugal, the quadratojugal, the maxilla, the premaxilla and the occipital parts of squamosal are free from sculpturing (Figs 1,2). There is room for at least five teeth on the premaxilla and the maxilla bears up to 30 conical teeth (Fig. 2A). The mode of tooth attachment is uncertain, as sediment obscures the tooth bases in all specimens. The anterolateral portions of the maxilla, the premaxilla and the nasal are extremely concave around the external naris, separated by a bony ridge from a wide concavity on the lacrimal that borders the orbit (Figs 1D, 2A, C). The anterolateral maxillary foramen is also situated inside the concavity of the maxilla (Figs 1D, 2A). The proportions and extent of the depression around the naris are unique to Nyctiphruretus within the Parareptilia. The sculptured dorsal portions of the prefrontal and the lacrimal form a ledge that overhangs the depression (Figs 1D, 2A, C).

The suture patterns between the different elements of the skull in dorsal view are well preserved in PIN 4659/1, illustrating the extent of each element, except the postparietal of which only a small sliver has been preserved (Fig. $2 \mathrm{~A}$ ). In the majority of Nyctiphruretus skulls, the posterior border of the skull is extremely poorly preserved and the postparietal is either missing or cannot be distinguished from the parietal (Fig. 3A) but a complete postparietal, which is a single medial element with a pointed tip, can be seen in PIN 158/5 (Fig. 3B). It is clearly a part of the dorsal portion of the skull, and not an occipital element like it is in many other parareptiles. A small tabular bone is also present, situated occipitally, ventral to the postparietal and next to the supraoccipital (Figs 2B, 3B). The lateral temporal region is slightly damaged in PIN 4659/1 but there appears to be an emargination between the jugal and the quadratojugal (Fig. 2A, C). The quadratojugal is more complete in PIN 158/7 and PIN 4660/18 (Figs 4, 

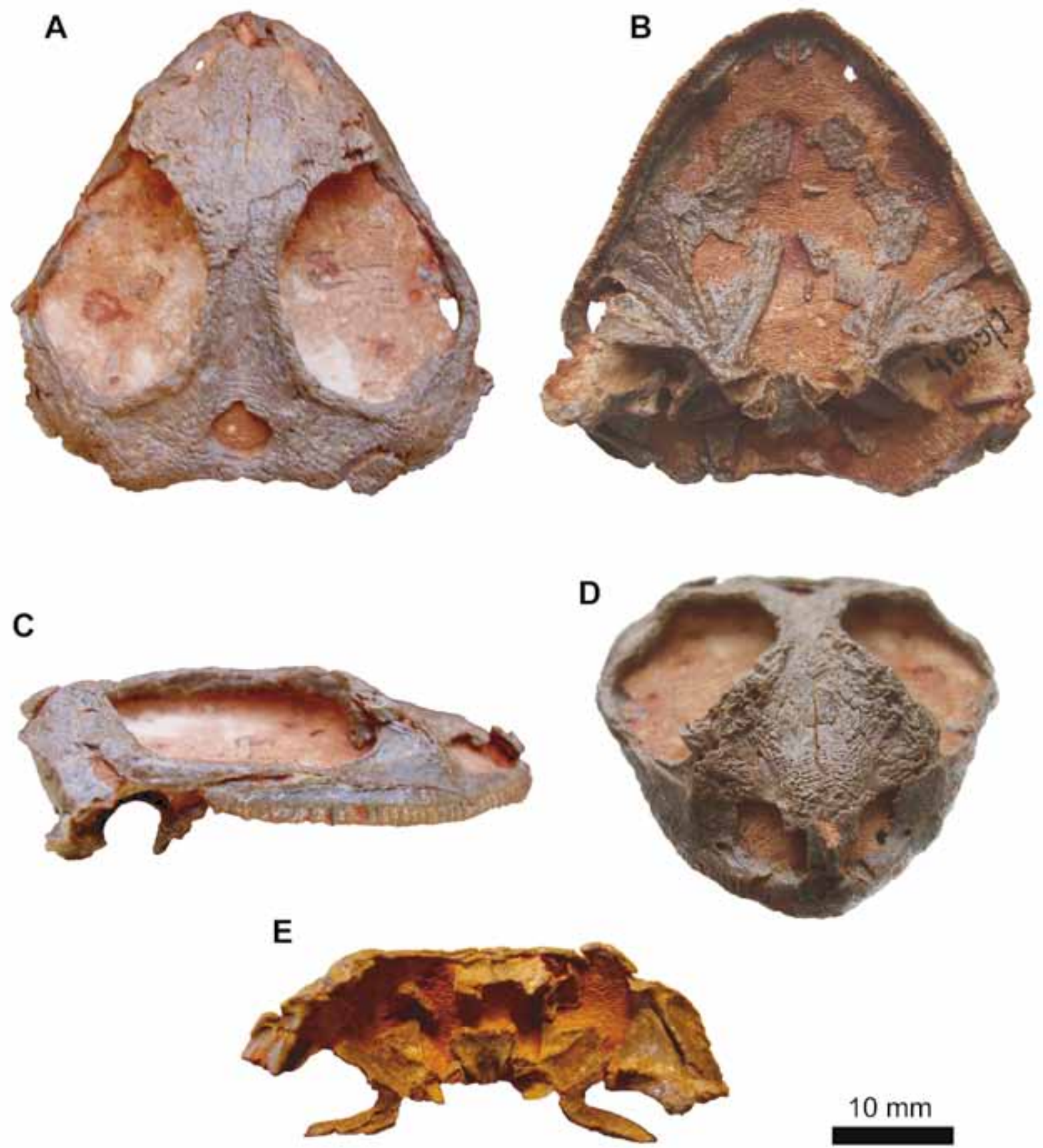

$10 \mathrm{~mm}$

Fig. 1.- Skull of Nyctiphruretus acudens, PIN 4659/1,from the Permian of Mezen River (Rusia) in, A, dorsal; B, palatal; C, right lateral; $\mathrm{D}$, anterior, and E, occipital views.

Fig. 1.- Cráneo de Nyctiphruretus acudens, PIN 4659/1, del Pérmico de Mazen River (Rusia) en vistas A, dorsal; B, palatal; C, lateral derecha; D, anterior, y E, occipital.

5A) - the emargination can be seen as being narrow and the anterior tip of the quadratojugal curves close to the posterior tip of the maxilla (Figs 4, 5A). The tip does not touch either the maxilla or the jugal, as can be seen in PIN 4660/18 (Fig. 5A), which is not as badly crushed transversely as in PIN 158/7 (Fig. 4). There is a narrow shelf at the posterolateral corners of the skull on the su- pratemporal, the squamosal and the quadratojugal above the posterior temporal emargination, also called temporal notch, (Fig. 2A), which in Nyctiphruretus is formed by the squamosal and the quadratojugal (Fig. 2C-D). The medial border of the emargination is attached to the dorsal expansion of the quadrate, which is contacted by a large posterodorsal expansion of the pterygoid (Fig. 2D). 
A

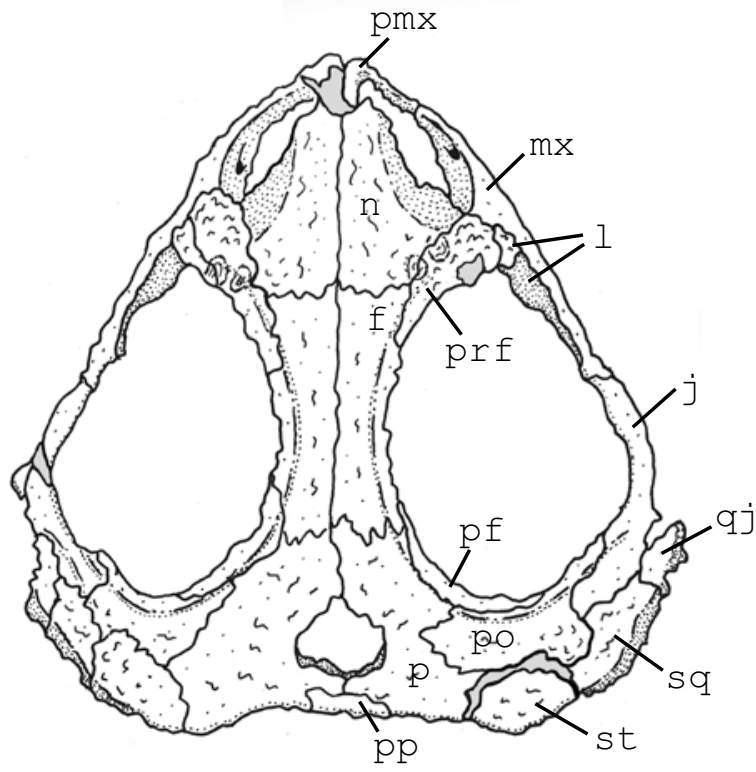

C

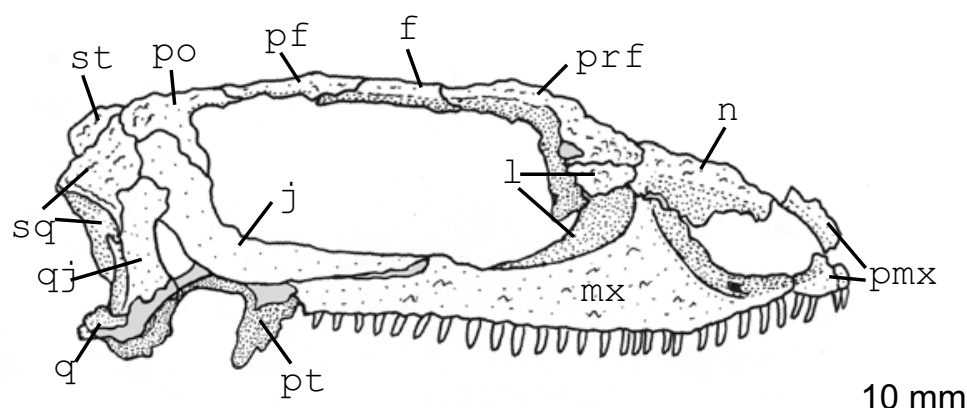

B

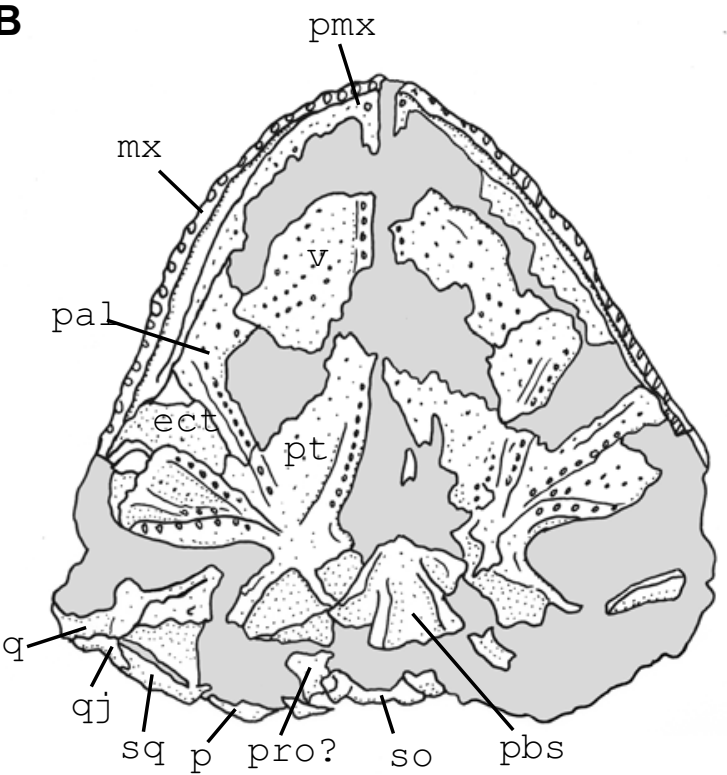

D

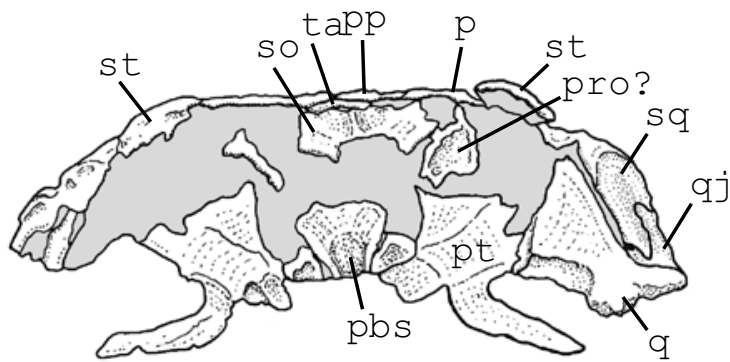

Fig. 2.- Drawing of the skull of Nyctiphruretus acudens, PIN 4659/1, in A, dorsal; B, palatal; C, right lateral, and D, occipital views.

Fig. 2.- Dibujo del cráneo de Nyctiphruretus acudens, PIN 4659/1, en vistas A, dorsal; B, palatal; C, lateral derecha y D, occipital.

\subsection{Palate and braincase}

The palate is extensively covered by denticles and rows of teeth are present on the vomer, the palate and the pterygoid (Fig. 6). The vomer and palatine are wide bones, and together they form the medial and posterior border of the choana (Figs 2D,6B). The palatine also contributes to the posterolateral margin of the choana (Fig. 2B). The ectopterygoid is devoid of teeth and occupies a small lateral corner between the palatine and pterygoid (Figs $2 \mathrm{~B}, 6 \mathrm{~B})$. The interpterygoid vacuity is fairly long and the anterior end of the pterygoids echoes its shape (Fig. 6B). The transverse flange of the pterygoid is concave with tooth rows running along its edges (Fig. 2B). It is separated by a bony ridge from the quadrate process of the pterygoid, which has two concave surfaces; one facing posteriorly and the other above posterodorsally (Fig. 2D). The quadrate process makes extensive contact with the dorsal flange of the quadrate (Fig. 2D).

Ventrally, the parabasisphenoid becomes broader posteriorly (Figs 2B, 6A-B). The cultriform process is fairly long and tapers to a sharp point (Fig. 6A-B). An element tentatively identified as the prootic has a concave surface in occipital view (Fig. 2D). Only small slivers of the opisthotic and the basioccipital can be seen in the studied specimens (Fig. 6B) but Ivakhnenko (1979) illustrated various (reconstructed) views of the braincase, including details of the basisphenoid, the basioccipital and the prootic, based on specimens that were not available for this study. However, the supraoccipital is nicely preserved in PIN 4659/1 (Fig. 2B, D). The posterior end of the supraoccipital has shifted ventrally in this specimen, exposing its dorsal surface, and has a low sagittal crest (Fig. 2D). The supraoccipital is also dorsoventrally compressed (Fig. 2B), and is nearly identical in shape to the supraoccipital of Macroleter (Tsuji, 2006). 

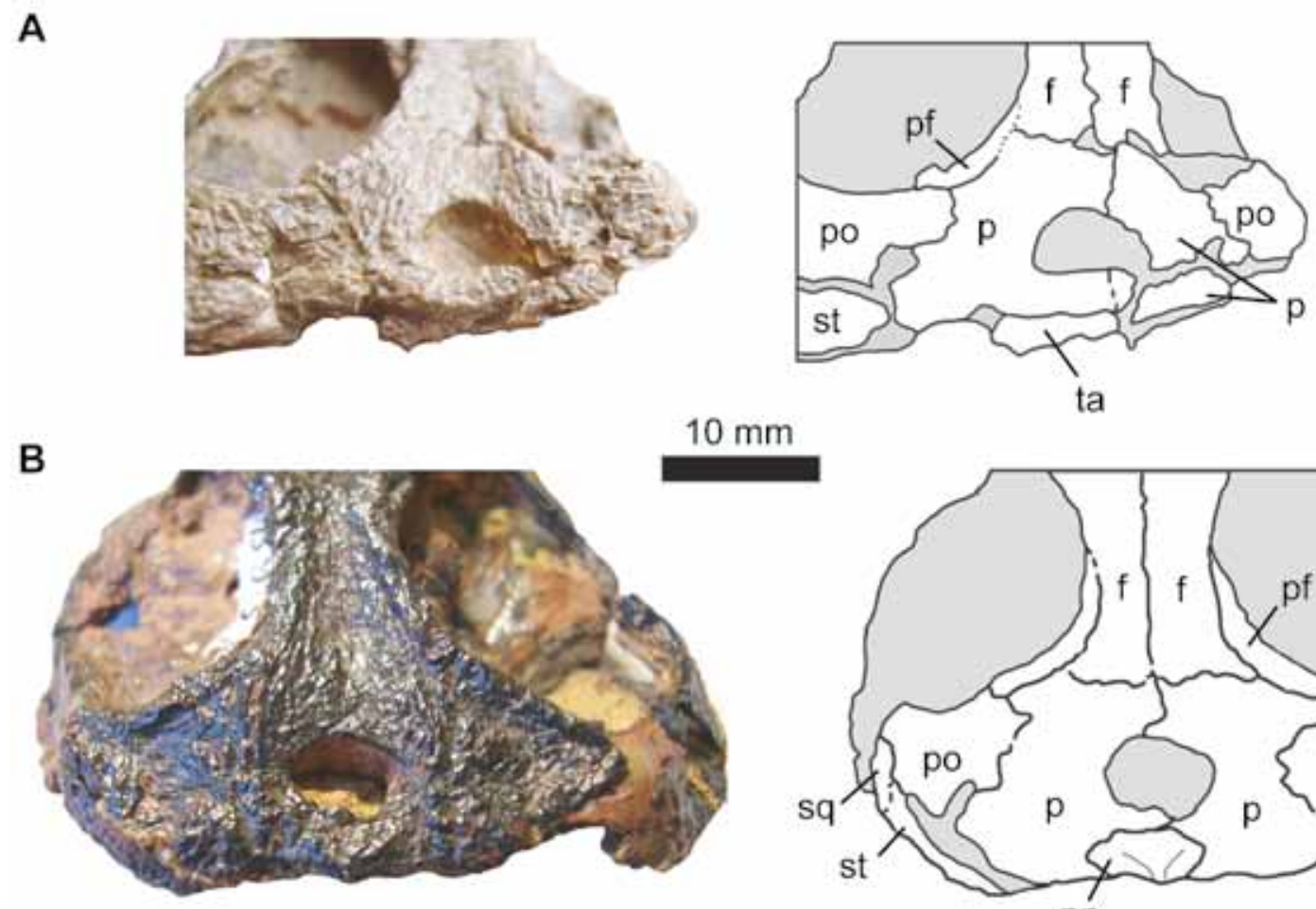

$10 \mathrm{~mm}$

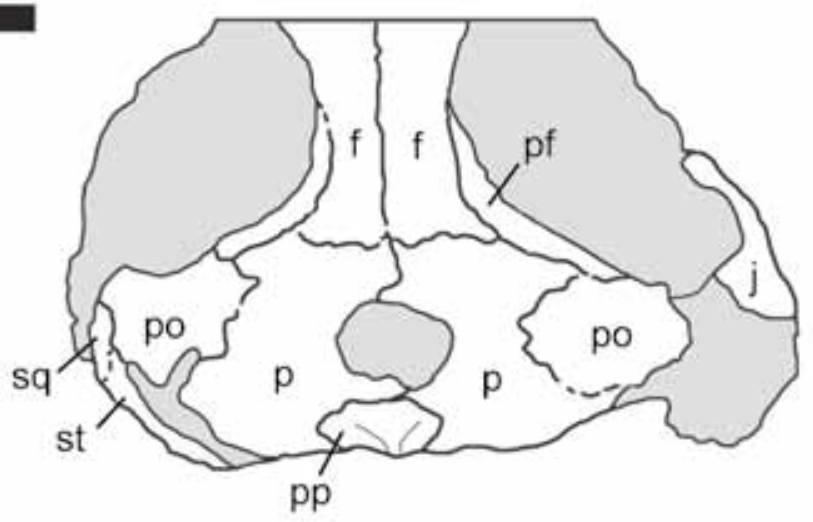

Fig. 3.- Photographs and interpretative drawings of the skull of Nyctiphruretus acudens, A, PIN 158/4, and B, PIN 158/5 in posterodorsal view.

Fig. 3.- Fotografías y dibujos de interpretación del cráneo de Nyctiphruretus acudens, A, PIN 158/4, y B, PIN 158/5 en vista posterodorsal.

\subsection{Mandible}

The mandible of Nyctiphruretus is shallow throughout its length (Figs 4, 5, 6). The dentary bears a meckelian groove on its medial side (Fig. 6B), although most of it is covered by the splenial, which does not reach the symphysis (Fig. 6A). Posteriorly, the dentary contributes to the low coronoid eminence with the surangular (Fig. 5B). The coronoid bone cannot be seen in any specimen but is most likely confined to the medial side of the mandible, and does not contribute to the laterally visible coronoid eminence. The surangular bears a shelf on the lateral side above its margin with the angular (Fig. 4B) and contributes to the lateral border of the retroarticular process (Fig. 4A). The angular curves around the ventral edge of the mandible and continues to the medial side (Fig. 6B). The prearticular cannot be seen in any specimen. The articular is transversely broadened and concave dorsally (Fig. $4 \mathrm{~A}-\mathrm{B}$ ), forming the dorsal part of the retroarticular process and making contact with the quadrate.

\section{Phylogenetic affinities of Nyctiphruretus}

Two recent papers (Tsuji 2006; Müller and Tsuji 2007) have included Nyctiphruretus in a phylogenetic study of parareptilian relationships. However, Nyctiphruretus was not the focus of either study and acted merely as a comparative taxon to help resolve the phylogenetic position of the closely related parareptile Macroleter (Tsuji 2006) and to address the evolution of the hearing apparatus in other parareptiles from the Mezen River basin (Müller and Tsuji 2007). The position of Nyctiphruretus remained unresolved within Parareptilia in the strict consensus tree of Müller and Tsuji (2007) but Tsuji (2006) recovered Nyctiphruretus as the sister group of a clade consisting of Macroleter and Pareiasauria in the single MPT (most parsimonious tree) of her analysis. Both analyses are rescored here for Nyctiphruretus and the members of Procolophonoidea, with comments concerning the re-scoring where appropriate.

\subsection{Tsuji (2006) analysis rescored}

The analysis of parareptilian relationships by Tsuji (2006) used 89 characters, of which two were new and the others taken and/or modified from previous analyses by Laurin and Reisz (1995), deBraga and Reisz (1996), deBraga and Rieppel (1997), Lee (1993, 1997), and Modesto (1999). All characters were cranial, and, apart from Macroleter that was the focus of the Tsuji (2006) 
study, all taxa were scored based on published descriptions or previous analyses. Because only a small number of well-known taxa were included in the Tsuji (2006) analysis, scorings of all characters for all the taxa (except Eudibamus) could be checked and modified when needed. The ingroup taxa (with references used in this revised analysis) were: Macroleter (Tsuji, 2006), Eunotosaurus (Cox, 1969; Gow, 1997), Millerettidae (Gow, 1972; Carroll and Lindsay, 1985 fig. 2b), Acleistorhinus (deBraga and Reisz, 1996), Lanthanosuchus (deBraga and Reisz, 1996; Lee, 1997), Belebey (Reisz et al., 2007), Procolophon (Carroll and Lindsay, 1985; Cisneros, 2008c; pers. obs. on BMNH R514 and SAM-PK-K7890), Owenetta (Reisz and Scott, 2002), Barasaurus (Cisneros, 2008c; pers. obs. on SAM-PK-8282), Bradysaurus (Lee, 1997), Scutosaurus (Lee, 1997, 2000), and Nyctiphruretus (this study; Ivakhnenko,1979 for some braincase characters). Scorings for Eudibamus could not be checked because the details of the skull are not illustrated or discussed in detail in any publication, and were left unaltered. As in the Tsuji (2006) analysis, Synapsida, Captorhinidae and Mesosauridae were assigned as outgoups when running the parsimony analysis in PAUP. However, this arrange- ment was not enforced by constraining these taxa outside a monophyletic ingroup, and with the scoring changes I made for Mesosauridae, it assumed a position within the ingroup (see 'Results and discussion' for more details). To score Synapsida, Tsuji (2006) followed the example of Laurin and Reisz (1995) by using the condition of four basal composite taxa (eothyrids, caseids, varanopids and ophiacodontids). Here, the scorings for these composite taxa were checked against Berman et al. (1995), Brinkman (1988), Dilkes and Reisz (1996), Langston (1965), Laurin and Reisz (1995), Reisz (2005), Reisz and Laurin (2004) and Romer and Price (1940). However, as many authors (e.g. Griswold et al. 1998; Kron and Judd 1997; Prendini 2001; Wiens 1998; Yeates 1995) believe using actual species/genera as terminals in an analysis, even if only a few species are included from each higher taxon, is a superior method to using supraspecific or composite terminals in many respects, a compromise decision was taken here to allow for multistate scoring for each supraspecific terminal if the taxa used to score for that terminal differed in their condition in respect to that character state. For Captorhinidae, scorings were checked against the basal taxa Romeria (Clark and Carroll, 1973)
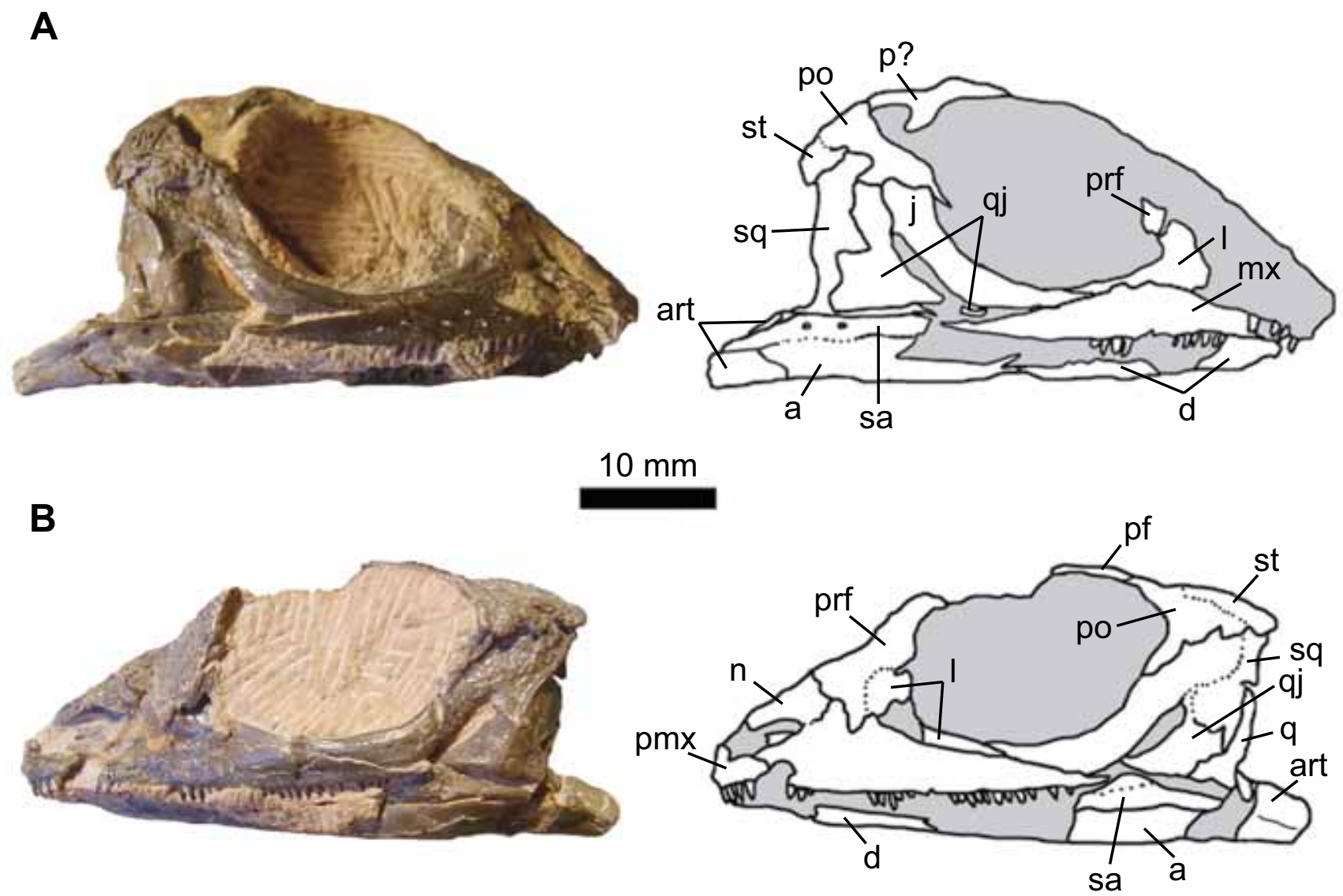

Fig. 4.- Photographs and interpretative drawings of the skull of Nyctiphruretus acudens, PIN 4660/18, in A, right lateral and B, left lateral view.

Fig. 4.- Fotografias y dibujos interpretativos del cráneo de Nyctiphruretus acudens, PIN 4660/18, en vistas A, lateral derecha y B, lateral izquierda. 

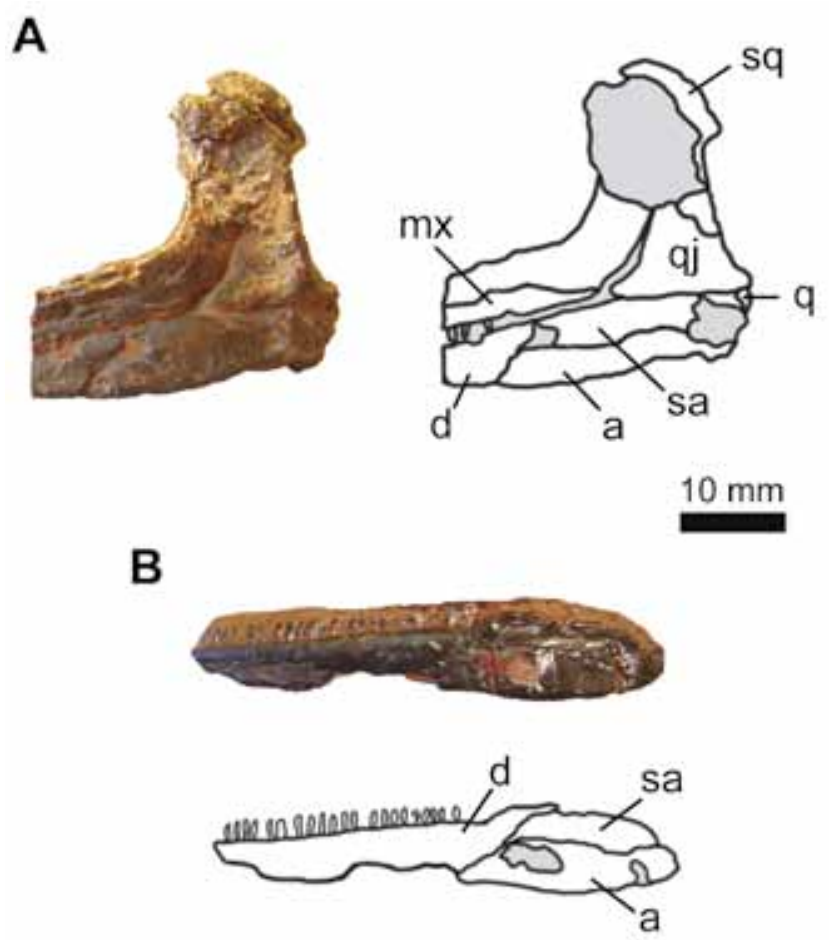

Fig. 5.- Photographs and interpretative drawings of Nyctiphruretus acudens. A, left temporal region of the skull PIN 158/7 in lateral view; B, partial left mandible PIN 158/6 in lateral view.

Fig. 5.- Fotografías y dibujos interpretativos de Nyctiphruretus acudens. A, región temporal izquierda del cráneo PIN 158/7 en vista lateral; B, fragmento de mandíbula izquierda PIN 158/6 en vista lateral.

and Concordia (Müller and Reisz, 2005), and for Mesosauridae against Mesosaurus (Modesto, 2006) and Stereosternum (Modesto, 1999). Only the characters that needed clarification and/or were rescored for Nyctiphruretus or other taxa are discussed here (the number of each character is in parentheses); a full list of characters can be found in Tsuji (2006).

\section{Narial shelf present or absent (1)}

The presence of a narial shelf has long been considered a synapomorphy of the Procolophonoidea (Laurin and Reisz, 1995; Tsuji, 2006). In analyses of procolophonoid interrelationships, the same condition has been called the 'presence or absence of a maxillary depression behind the external naris' (Modesto and Damiani, 2007; Säilä, 2008). All procolophonoids do possess a narial shelf of some description, but there are considerable differences in the extent of this shelf. In Owenettidae (represented by Owenetta and Barasaurus in Tsuji, 2006) the shelf is very narrow, and only visible on the nasal, but not on the maxilla, in lateral view. In Procolophonidae, on the other hand, the narial shelf is broad and visible on the maxilla (and nasal) in lateral view. Although never before acknowledged in a phylogenetic context, Nyctiphruretus also has a narial shelf. The dimensions of this shelf far exceed the dimensions of the shelf in Procolophonidae, as it continues all around the external naris, and extends to the premaxilla also (Figs 1 and 2). Nevertheless, a narial shelf is clearly present in Nyctiphruretus and the scoring of this character was changed accordingly.

\section{Postparietal integrated into skull table or occipital (6)}

The postparietal of Nyctiphruretus has previously been interpreted as being in an occipital position (Ivakhnenko, 1979; Lee, 1995; Tsuji, 2006). This is incorrect, as the single, medial postparietal is clearly a part of the skull table (Figs 2A, 3B). Scoring was changed accordingly.

\section{Tabular size/absence (17)}

The tabular bone of Nyctiphruretus is small and situated occipitally (Figs 2B, 3A), whereas all procolophonoids lack the tabular bone. Macroleter also has a small, occipitally-situated tabular (Tsuji, 2006). The description and discussion of Tsuji (2006) recognises this but this character has been scored incorrectly for Procolophon (small tabular present), and Nyctiphruretus and Macroleter (no tabular present). The scorings for all three taxa were changed to reflect their true condition.

\section{Maxilla and quadratojugal separated or in contact (22)}

Tsuji (2006) scored the maxilla and the quadratojugal as being in contact in Nyctiphruretus based on illustrations of Ivakhnenko (1979) and Lee (1995, 1997), when in fact they are not due to a temporal emargination between the quadratojugal and the jugal (Fig. 5A). However, as temporal emargination is addressed in character 35 (see discussion below), this character is considered inapplicable for taxa with lateral temporal emargination. Thus, Nyctiphruretus, Procolophon, Owenetta, and Barasaurus are scored as '?'. In addition, the scoring of Mesosauridae, Millerettidae and Captorhinidae is corrected to ' 0 ' as the maxilla and quadratojugal are clearly separated by the jugal in these taxa (Gow, 1972; Modesto, 2006; Clark and Carroll, 1973) and to '0\&1' for synapsids as these bones are connected in caseids, eothyrids and some varanopids but separated in other varanopids and ophiacodontids (Berman et al., 1995; Brinkman, 1988; Langston, 1965; Laurin and Reisz, 1995; Romer and Price, 1940).

\section{Quadratojugal lateral temporal fenestra contribution (32)}

Tsuji (2006) took this character from the analysis of deBraga and Reisz (1996), where only lanthanosuchids were scored as having a quadratojugal that contributed to the lateral temporal fenestra. Tsuji (2006) rescored this so that all parareptiles except Millerettidae have quadratojugal contribution to the lateral temporal fenestra but it 
A

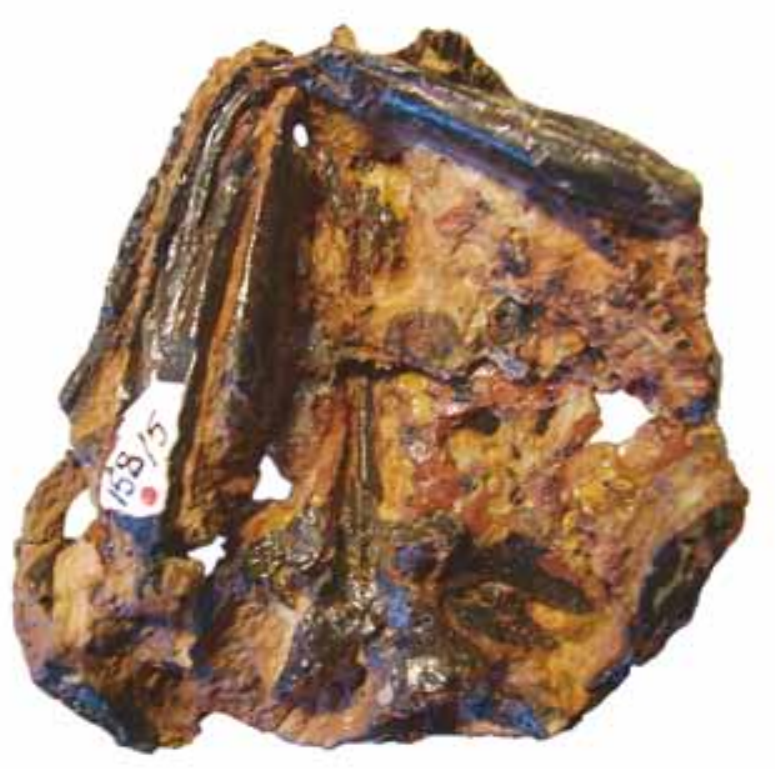

$10 \mathrm{~mm}$
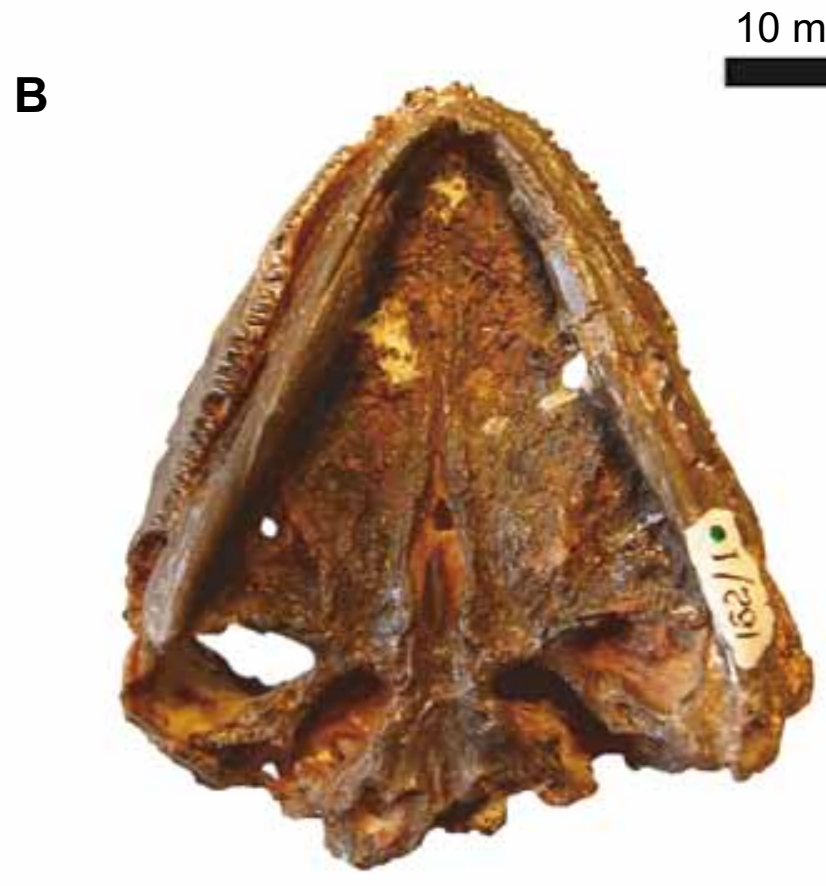

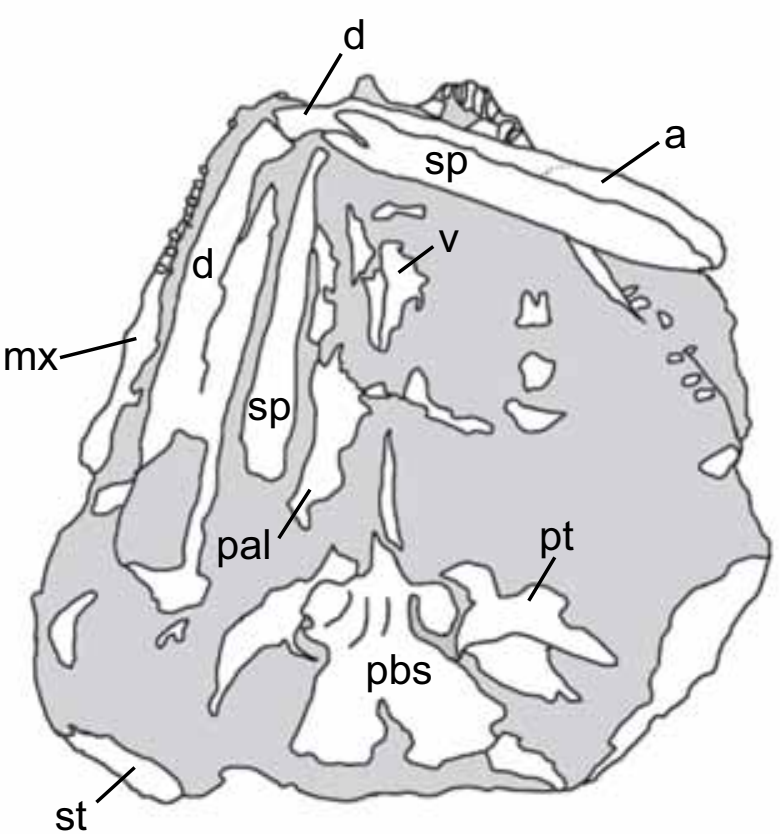

st

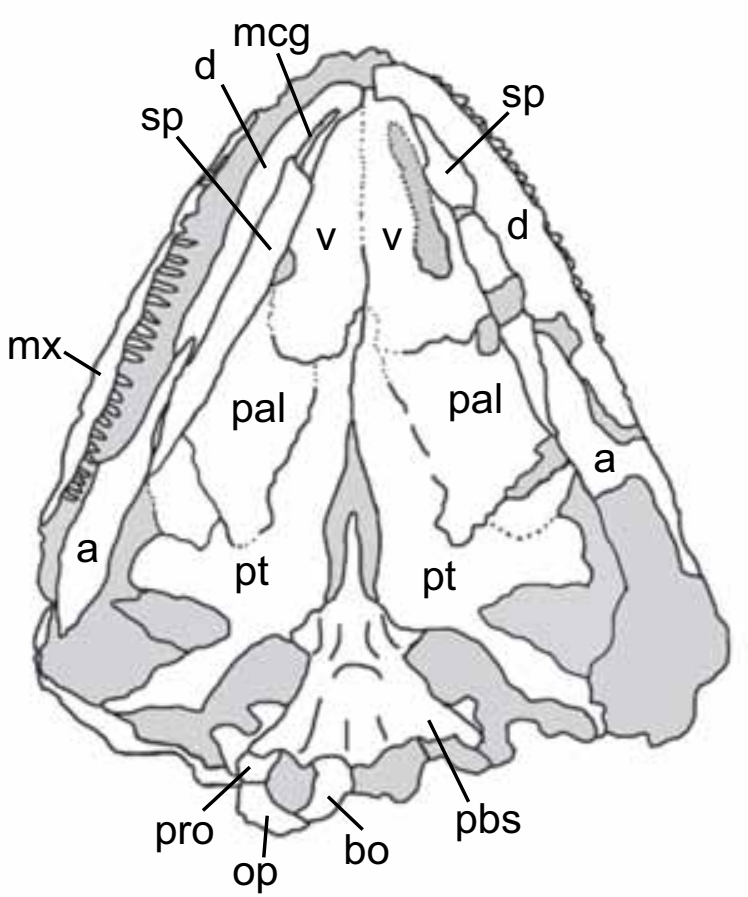

Fig. 6.- Photographs and interpretative drawings of the palatal view of the skull and mandible of Nyctiphruretus acudens. A, PIN 158/5, and B, PIN 162/1.

Fig. 6.- Fotografías y dibujos interpretativos de la vista palatal del cráneo y mandíbula de Nyctiphruretus acudens. A, PIN 158/5, and B, PIN $162 / 1$.

appears that millerettids are polymorphic in this feature (Gow, 1972). Furthermore, the character is also polymorphic in synapsids, because caseids and varanopids have a quadratojugal contribution to the lateral temporal fenestra but eothyrids and ophiacodontids do not (Berman et al., 1995; Brinkman, 1988; Langston, 1965; Laurin and Reisz, 1995; Romer and Price, 1940). This leads to a situation where no taxon is unambiguously scored ' 0 ' because in all other other taxa this feature is either present
(1) or unknown/inapplicable (?).Thus, this character does not offer any parsimonious information for the taxa included in this analysis. However, as deleting this character would change the numbering sequence of the following characters, which in turn would make comparison with the original Tsuji (2006) analysis difficult, it was left in the analysis. Furthermore, this character has potential to be parsimony informative if more taxa were added into the analysis in the future. 
Ventral margin of the postorbital skull region (35)

The ventral margin of the lateral temporal region was scored as rectilinear in Nyctiphruretus by Tsuji (2006). This is how the reconstructions of Ivakhnenko (1979) and Lee $(1995,1997)$ depicted the skull, but in fact there is a narrow emargination between the jugal and quadratojugal (Figs. 2A, 4, 5A). The emargination of the lateral temporal margin is also present in procolophonoids (narrow in owenettids and wide in procolophonids). An emargination was also scored as present in Eunotosaurus by Tsuji (2006), but as the skull of Eunotosaurus is only known from two fragmentary specimens (Cox, 1969; Gow, 1997) and the elements of the lateral temporal region of the better preserved skull have become separated (Gow, 1997 fig. 2), it is uncertain whether Eunotosaurus had a true temporal emargination. Thus, the scoring for Eunotosaurus was changed to '?'.

\section{Posterior margin of the skull roof (41)}

The plesiomorphic state for this character is bilaterally embayed. This is found in synapsids and basal captorhinids where the posterior margin of the skull is formed by the margins of the tabulars, the supratemporals and the parietals (Müller and Reisz, 2005; Reisz and Laurin, 2004). The skull of Nyctiphruretus was scored as having a single medial embayment by Tsuji (2006), but all other taxa that are scored as having this state, including Macroleter, have a posterior margin with a deep inverted v-shape. The posterior margin of the skull of Nyctiphruretus is somewhat concave (Fig 1A, 2A), but this concavity is separated into two portions by the protruding postparietal that is part of the skull table (Fig. 3B). The same structure can be seen in Owenetta kitchingorum (Reisz and Scott, 2002), and Barasaurus (Cisneros, 2008c, pers. obs. on SAM-PK$\mathrm{K} 8282)$. As this bilaterally embayed state is formed differently from the structure seen in synapsids and captorhinids, a new character state is created to accommodate it; posterior margin of the skull slightly concave, with a projecting medial postparietal(s) (3). In Procolophon, however, there are no separate postparietals as they have either fused into the parietals or been lost, and the margin of the parietals is variable between straight (Carroll and Lindsay, 1985) and bilaterally embayed (Cisneros 2008c). Thus, Nyctiphruretus, Owenetta and Barasaurus were scored as ' 3 ' and Procolophon as '0\&2'.

\section{Palatine contribution to the palate (46)}

The palatine of Nyctiphruretus is scored as narrow (less than $50 \%$ of the width of the pterygoid) by Tsuji (2006). It is understood that this refers to the maximum width of the palatine, and in fact the palatine of Nyctiphruretus is quite broad (Figs 2B, 6B). The scoring was changed accordingly.

\section{Transverse flange of pterygoid orientation (51)}

The transverse flange orientation of Nyctiphruretus is scored as being posterolateral by Tsuji (2006). However, the orientation (Figs 2B and 6B) of the flange is clearly similar to that of Owenetta (Reisz and Scott, 2002), Procolophon (Carroll and Lindsay, 1985) and Macroleter (Tsuji, 2006) and was thus rescored as 'directed anterolaterally' for Nyctiphruretus.

\section{Ectopterygoid dimensions (54) and dentition (55)}

Tsuji (2006) scored Nyctiphruretus as having a long ectopterygoid with dentition on it. This is clearly based on the reconstructions of Lee $(1995,1997)$ but the ectopterygoid is actually a small bone constrained to a corner between the tooth rows of the palatine and the pterygoid (Figs 2B, 6B) and is devoid of dentition. Scoring was changed accordingly.

\section{Parasphenoid wings present or absent (61)}

This character is problematic as the definition of 'parasphenoid wings' is not clear. Many authors (e.g. Olson, 1947) use 'parasphenoid wings' when referring to the basitubera but it has been understood that Laurin and Reisz (1995), who originally created this character, used it strictly as a dimensional character (Modesto, 1998, 2006). However, this is not the case and in fact Laurin and Reitz (1995) used 'parasphenoid wings' to describe a condition where the wing is a raised, posterior extension of the parasphenoid that extends beyond its central depressed portion posteriorly. Nevertheless, Tsuji (2006) amended the diagnosis for 'wings present' to equal 'parasphenoid is broader than long'. This state was correctly scored for Synapsida and Eunotosaurus but Mesosauridae were scored incorrectly, as the parasphenoid of Mesosaurus is slightly longer that it is broad (Modesto, 2006 fig. 1c). The scoring was changed accordingly.

\section{Morphology of marginal dentition (77)}

There are two states for this character, single cusp (0) or two or more cusps (1), in Tsuji (2006), and only pareiasaurs (Bradysaurus and Scutosaurus) are coded as having state one. However, the teeth of pareiasaurs are leaf-shaped with small denticles running along the apex (Ivakhnenko, 1987; Lee, 2000), and it is debatable whether these should be called cusps. Furthermore, the teeth of Procolophon are transversely broadened with two cusps (pers. obs. on Procolophon trigoniceps, BMNH R514 and SAM-PK-K7890), a character shared with many other procolophonids. As this tooth structure cannot be 
treated as identical to the condition seen in pareiasaurs, a third character state (teeth leaf-shaped with several denticles) was erected for the pareiasaurian condition and state two was changed to 'with two cusps'. Thus, Procolophon alone (as other derived procolophonids are not included into this analysis) was scored as having teeth with two cusps (1), and Scutosaurus and Bradysaurus with leafshaped teeth with denticles (2).

\section{Fossa meckelii long or short (80)}

This character is originally from Reisz and Laurin (1995) where, based on the description of Procolophon by Carroll and Lindsay (1985), a short (less than $20 \%$ of the total length of the lower jaw) fossa meckelii (also called adductor fossa) was scored for procolophonians. However, the illustration of the lower jaw of Procolophon in Carroll and Lindsay (1985, fig. 13), which Reisz and Laurin (1995) used as their source, has a fossa meckelii that is $21 \%$ of the whole length of the jaw. Thus, if the fossa meckelii in Procolophon is understood as short, new definitions are needed. In this study, a short fossa meckelii is understood as 'less than $25 \%$ of the length' and a long one as 'more than $25 \%$ of the length' of the lower jaw. The fossa meckelii cannot be seen in Nyctiphruretus but mesosaurs (estimated from Modesto 2006 fig. 12) appear to possess a short fossa, as does Procolophon, which was scored as '?' for this character in Tsuji (2006), and the scorings were changed to ' 1 ' for both.

\section{Surangular length (81)}

The surangular of Nyctiphruretus does not extend beyond the coronoid eminence (Fig. 5B), and scoring was changed to ' 1 ' for this character.

\section{Accessory lateral shelf of surangular (82)}

Anterior to the articular region, there is a accessory lateral shelf present on the surangular, so scoring for Nyctiphruretus (Fig. 4B) was changed to ' 1 ' for this character.

\section{Retroarticular process presence/shape (85)}

The retroarticular process of Nyctriphruretus is transversely broad and dorsally concave (Fig. 4A-B), scoring was changed to ' 1 ' for this character.

\section{Retroarticular process composition (86)}

The retroarticular process of Nyctiphruretus is composed of at least the articular, the surangular and the angular (Fig. 4), so scoring was changed to ' 1 ' for this character.

\section{Splenial symphysis contribution (89)}

The splenial of Nyctiphruretus is excluded from the symphysis (Fig. 6A), and thus scoring was changed to ' 1 ' for this character.

Additionally, previously unknown characters for $\mathrm{Nyc}$ tiphruretus were scored as follows: quadrate ramus of pterygoid with deep excavation on the posterolateral surface (53:1) and sagittal crest of supraoccipital present (64:1). Also, contact between paraoccipital process and the dermatocranium, which was previously scored as unknown, was scored as absent (67:4) for Mesosauridae, Eunotosaurus, and Belebey, and changed from '1' (to squamosal and supratemporal) to '4' (absent) for Millerettidae. Because such a high number of characters were rescored for Nyctiphruretus, and other taxa, the modified matrix is included in Appendix 1 (a NEXUS formatted matrix is also available as an electronic supplement).

The modified data set was analysed using the branchand-bound algorithm with DELTRAN optimization in PAUP* 4.0b10 (Swofford, 2002). Characters were left unweighted and unordered. Bootstrap analysis (1000 replicates) and decay analysis were also performed using PAUP* 4.0b10 and TreeRot 2.0 (Sorenson, 1999). These are the same settings used in the analysis of Tsuji (2006). MacClade 4.06 (Maddison and Maddison, 2003) was used in modifying the original data set and for identifying synapomorphies.

\section{Results and discussion}

A single MPT was found, with a tree length of 197 without uninformative characters (202 with uninformative characters). The consistency index was 0.558 (0.569), the retention index was 0.691 , the homoplasy index was $0.442(0.431)$, and the rescaled consistency index was $0.386(0.394)$. Bootstrap and decay analysis, as well as the Templeton test, were performed on the data matrix that had uninformative characters excluded. The MPT, along with the results of the bootstrap and decay analyses, are shown in Figure 7.

The resulting MPT differs from the single MPT of the original Tsuji (2006) analysis and other previous analyses to a considerable degree. Firstly, Mesosauridae, which was one of the three outgroups of Tsuji (2006), is recovered within the ingroup Parareptilia because it is positioned nesting deeper in the topology than the Millerettidae-Eunotosaurus clade (B), which is called Millerosauria sensu Modesto and Reisz (2008). In Tsuji (2006) 'Parareptilia' includes millerettids, lanthanosuchids, bolosaurs, procolophonoids, pareiasaurs, and 'nyctipthruretians' (Macroleter and Nyctiphruretus) and Mesosauria is the sister-group of 'Parareptilia'. However, Modesto (2006), who obtained a similar topology to Tsuji (2006), pointed out that the more inclusive clade ('Parareptilia' sensu Tsuji 2006 and Mesosauridae) could be applied the name 'Anapsida' sensu Gauthier (1994), 'Pararep- 


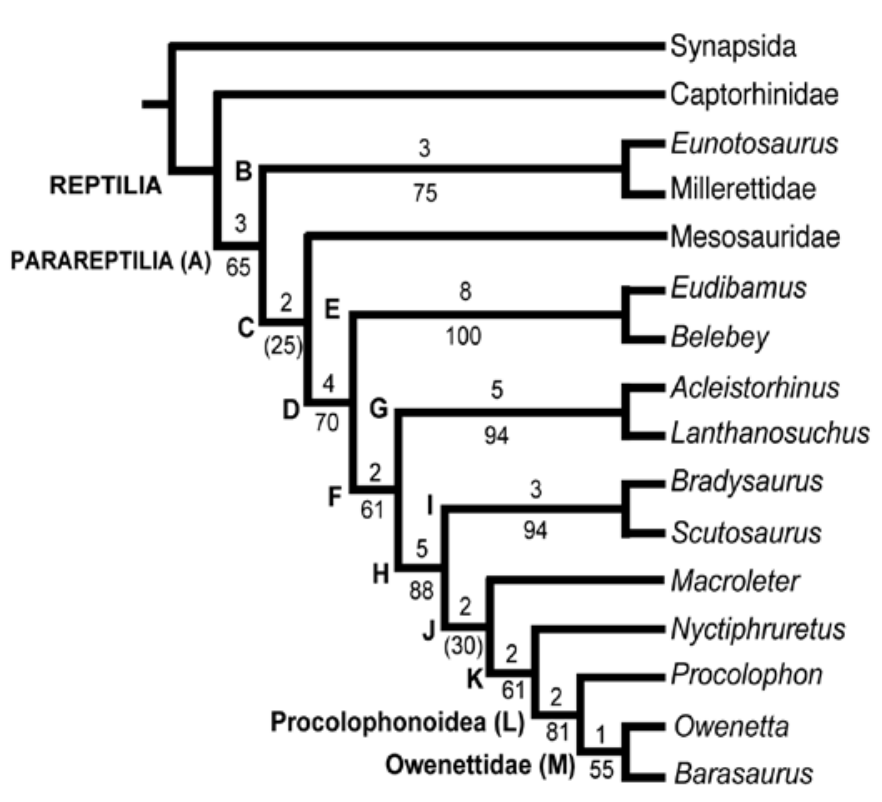

Fig. 7.- The single most parsimonious trees from an analysis of parareptilian interrelationships, Tsuji (2006) data matrix rescored. Bootstrap frequencies are indicated below and decay values above each node. See text for tree statistics and discussion.

Fig. 7.- El único árbol más parsimonioso de las interrelaciones de parentesco de parareptiles, basada en Tsuji (2006) con la matriz de datos recodificada. Las frecuencias de Bootstrap se indican debajo y los valores de decaimiento encima de cada nodo. Véase el texto para los estadísticos del árbol y su discusión.

tilia' sensu Laurin and Reisz (1995) or 'Proganosauria' sensu Modesto (1999). Nevertheless, Mesosauridae has not previously been recovered nested within the Parareptilia in the way it is found here (Fig. 7). The support for this position is not strong, with a decay value of 2 and bootstrap support of only $25 \%$, but it does lend further support to the possibility that Mesosauridae is a member of the Parareptilia, a position most recently suggested by Modesto (2006).

The clades consisting of Eudibamus and Belebey (E, Bolosauridae) and of Acleistorhinus and Lanthanosuchus (G, Lanthanosuchoidea) also swapped positions in comparison to the Tsuji (2006) analysis, but the most interesting result was the new position of the 'nyctiphruretians' Nyctiphruretus and Macroleter. Nyctiphruretus was recovered as the sister group of Procolophonoidea and Macroleter as the sister group of the Nyctiphruretus-Procolophonoidea clade (Fig. 7). The Nyctiphruretus-Procolophonoidea $(\mathrm{K})$ clade has bootstrap support of $61 \%$ and a decay value of 2 , and is diagnosed by the following synapomorphies: narial shelf present (1:1); ventral margin of postorbital skull emarginated (35:2); posterior margin of skull roof slightly concave with protruding medial postparietal(s) (38:3); pterygoid anterior extent posterior to choana (39:1, ambiguous). This is the first time this position for Nyctiphruretus has been hypothesised in a phylogenetic analysis, although it has been previously suggested based on subjective classification studies $\mathrm{Bu}-$ lanov, 2002; Ivakhnenko, 1979, 1987, 1990; Tverdokhlebova and Ivakhnenko 1994). Clade J (K and Macroleter) also has a decay value of 2 but only $30 \%$ bootstrap support. In fact, bootstrap support was much better (56\%) for a clade consisting of Macroleter and the pareiasaurs (Scutosaurus and Bradysaurus) that was not recovered in the MPT of this analysis but was present in the MPT of Tsuji (2006).

Because this analysis used the data matrix of Tsuji (2006), with amended or corrected scorings for Nyctiphruretus and some other taxa, but the results are considerably different, some additional testing was done following the methods explained in Templeton (1983). In order to find out if the MPT recovered in this study was a significantly better fit to its source data than the MPT recovered by Tsuji (2006), a branch-and-bound analysis was rerun with constraints (the topology of the Tsuji, 2006 MPT). The result was a tree two steps longer (199 steps) and the Templeton test result of $p=0.64$ indicated there was no significant difference between the fits of the tree found in this study and the constraint tree for the data matrix used in this analysis. The same test was done for the original Tsuji (2006) data matrix, with the constraint being the topology recovered in this analysis. The resulting tree was four steps longer than the original MPT of Tsuji (2006), but again the results of the Templeton test $(p=0.317)$ indicated there was no significant difference between the fits of the constraint tree and the original topology to the data. In other words, statistically, neither topology is a better fit to either the original or the modified data matrix than the other. Thus, neither the position of Nyctiphruretus as the sister group of the Procolophonoidea found in this analysis or as the sister group to Pareiasauria + Macroleter found in Tsuji (2006) has statistically significantly better support than the other. However, as the results of this analysis are based on more complete knowledge of Nyctiphruretus, a sister-group relationship between Nyctiphruretus and Procolophonoidea is certainly possible and worth further investigation. Furthermore, clade $\mathrm{H}$, which includes Pareiasauria, Procolophonoidea, Macroleter and Nyctiphruretus, is well supported in both Tsuji (2006) and this analysis, indicating that these taxa are closely related but there is no consensus on their interrelationships.

\subsection{Müller and Tsuji (2007) rescored}

The analysis of parareptilian relationships of Müller and Tsuji (2007) was a revised and expanded version of 
previous phylogenetic studies of Laurin and Reisz (1995), Reisz et al. (2007) and Tsuji (2006). It included 137 parsimony-informative characters (cranial and postcranial) and 28 taxa. The Müller and Tsuji (2007) analysis was the first time all of the non-pareiasaurian parareptiles, except for the poorly known Rhiapaeosaurus tricuspidens, from the Mezen River basin of Russian were included in a phylogenetic analysis. Nyctiphruretus acudens is one of these parareptiles, the others being 'Bashkyroleter'bashkyricus, Bashkyroleter mesensis, Emeroleter levis, Macroleter poezicus, Nycteroleter ineptus, and Tokosaurus perforatus. In addition to these taxa, the analysis included Synapsida, Mesosauridae, Eunotosaurus, Millerettidae, Eudibamus, Belebey, Acleistorhinus, Lanthanosuchus, Bradysaurus, Pareiasuchus, Scutosaurus, Procolophon, Owenetta, Barasaurus, Captorhinidae, Paleothyris, Araeoscelidae, and Youginaformes as the ingroup taxa, and Seymouria, Limnoscelidae and Diadectidae as the outgroup taxa.

The published strict consensus of the 6 MPTs of the Müller and Tsuji (2007) analysis found the position of Nyctiphruretus and the Bolosauridae (Eudibamus and Belebey) unresolved within a grouping including the other Mezen River non-pareiasaur parareptiles, pareiasaurs and procolophonoids (Müller and Tsuji 2007 fig. 1). However, when studying the 6 MPTs, obtained by re-running the unchanged data matrix of Müller and Tsuji (2007) with the specified settings, the position of Nyctiphruretus is one of two: (1) it is the sister taxon of the clade including the other non-pareiasaur Mezen River parareptiles, procolophonoids and pareiasaurs, or (2) it is the sister taxon of a clade including all the above mention taxa and the bolosaurids. Furthermore, Modesto and Reisz (2008) found that when the parareptile Colobomycter pholeter was added to the Müller and Tsuji (2007) analysis, 75\% of the 12 recovered MPTs contained a clade where $\mathrm{Nyc}$ tiphruretus was recovered as the sister group to the clade containing the other non-pareiasaurian Mezen River parareptiles, procolophonoids and pareiasaurs (Modesto and Reisz, 2008, fig. 5A). As with the Tsuji (2006) data matrix, checking and modifying scorings for all taxa present in the analysis would be have been the best practice. However, although most taxa included in the Müller and Tsuji (2007) analysis have moderately good published descriptions, the non-pareiasaurian Mezen River parareptiles, except for Nyctiphruretus (this study) and Macroleter (Tsuji, 2006), have only been briefly described, accompanied by mostly reconstructed cranial images in limited views (Chudinov, 1957; Efremov, 1938; Ivakhnenko, 1983, 1987, 1997; Müller and Tsuji, 2007). Furthermore, no postcranial material has been described for any of these taxa, although information on the postcranial anatomy of Macroleter (and Nyctiphruretus) was included into the analysis based on personal observations by Müller and Tsuji (2007). Thus, modifying the scoring for the other included taxa, but not for the other non-pareiasaurian Mezen River parareptiles, could lead to serious inconsistencies within the resulting matrix. To avoid this scenario, only the scoring for Nyctiphruretus (this study and the postcranial material of PIN 158/4 and PIN 162) and the procolophonoids Procolophon (Carroll and Lindsay 1985; Cisneros 2008c; deBraga, 2003; pers. obs. on BMNH R514 and SAM-PK-K7890), Owenetta (Reisz and Scott, 2002) and Barasaurus (Cisneros, 2008c; Ketchum and Barrett, 2004; pers. obs. on SAMPK-8282) were checked and modified when mistakes/ scoring problems were noticed. The modification of two characters also had broader impact within the data matrix and these characters were also rescored for Bradysaurus and Eudibamus (see discussion below). Characters that needed clarification and/or were rescored are discussed here (the number of each character in parentheses); a full list of characters can be found in Müller and Tsuji (2007).

\section{Narial shelf present or absent (1)}

Narial shelf is present in Nyctiphruretus, scoring was changed to ' 1 '. See discussion for this scoring in section 4.1.

\section{Postparietal integrated into skull table or occipital (6)}

The postparietal of Nyctiphruretus is integrated into the skull table, and scoring was changed to ' 0 '. See discussion for this scoring in section 4.1.

\section{Maxilla and quadratojugal separated or in contact (21)}

This character was rescored as '?' for Nyctiphruretus, and the procolophonoids (Owenetta, Barasaurus, Procolophon) as the lateral temporal emargination of these taxa makes scoring of this character uncertain (see discussion for this scoring in section 4.1).

\section{Ventral temporal emargination (29)}

Müller and Tsuji (2007) have modified this character from previous analyses (Laurin and Reisz, 1995; Tsuji, 2006) to include not just the presence or absence of the lower temporal fenestra but have added a state where the lower temporal emargination is considered a variation of the lower temporal fenestra. The different states are: no lower temporal opening (0), temporal opening bounded (1) or open ventrally (2). Müller and Tsuji (2007) have correctly scored Nyctiphruretus and the procolophonoids as having a ventrally open emargination. This affects the scoring character 30 (see below). 


\section{Postorbital contribution to the lateral temporal fenestra (30)}

Because the lateral temporal emargination is considered a variation of the lateral temporal fenestra in character 29 (presence/absence of lateral temporal fenestra), the contribution of the postorbital to the border of the fenestra should be modified to include the border of the emargination as well. Thus, the wording for this character was changed to 'postorbital contribution to the lateral temporal opening (bounded or unbounded)', and as there is no postorbital contribution in the procolophonoids or Nyctiphruretus, the scoring was changed to ' 1 ' for the procolophonoids. Nyctiphruretus was already scored as 1' by Müller and Tsuji (2007).

\section{Quadratojugal lateral temporal fenestra contribution (31)}

This character was modified in all taxa with lateral temporal emargination for the reasons explained for character 30 (see above). Scoring for procolophonoids was changed to ' 1 ' (quadratojugal contribution present), Nyctiphruretus was already scored as ' 1 ' by Müller and Tsuji (2007).

Ventral margin of postorbital skull region expanded, rectilinear or emarginated (33)

As the third state of this character is the ventral margin being emarginated, it effectively doubles the impact of the ventral temporal emargination scored in character 29 for the procolophonoids and Nyctiphruretus (which was not scored as having an emargination in this character in the Müller and Tsuji, 2007 analysis). Moreover, many procolophonoids, including Procolophon to some degree but especially the leptopleuronine procolophonoids (which were not included in this analysis), have a wide expansion of the quadratojugal below the level of the margin of the maxilla, and should thus be scored as having two states of this character in the same taxon. Because of this, character 33 was modified to have only two character states: ventral margin of the postorbital skull region expanded below the level of the ventral margin of the maxilla (0), or rectilinear with the ventral margin of the maxilla (1). Taxa that have the ventral emargination are scored based on the ventral extent of the region of the skull behind the emargination. Thus, the postorbital region is scored as expanded in Procolophon and rectilinear in Owenetta, Barasaurus and Nyctiphruretus. Scoring for Eunotosaurus, which was scored as '2' (emarginated) by Müller and Tsuji (2007) is changed to '?' because of the poor preservation of this area in the known material.

\section{Posterior margin of the skull roof (40)}

As for the Tsuji (2006) analysis, a third character state (posterior margin slightly concave with a medially pro- truding postparietal/postparietals) was added to accommodate the condition seen in Nyctiphruretus, Owenetta and Barasaurus. Procolophon was scored as '0\&2' (bilaterally embayed/straight margin). See discussion for these scorings in section 4.1.

\section{Pterygoid anterior extent (46)}

Scoring for this character was changed to ' 1 ' (posterior to choana) for Nyctiphruretus based on PIN 162/1 (Fig. 6B).

\section{Transverse flange of pterygoid orientation (48)}

Scoring for this character was changed to ' 1 ' (anterolateral orientation) for Nyctiphruretus based on PIN 4659/1 and PIN 162/1 (Figs 2B, 6B).

Pterygoid qadrate ramus and transverse flange connections (50)

Scoring for this character was changed to ' 1 ' (deep excavation on posterolateral surface) for Nyctiphruretus based on PIN 4659/1 (Fig. 2D).

\section{Ectopterygoid dentition present or absent (51)}

Scoring for this character was changed to '1' (dentition absent) for Nyctiphruretus based on PIN 4659/1 (Fig. 2B).

\section{Supraoccipital presencelextent (60)}

Scoring for Nyctiphruretus was changed to '2' (body constricted forming a sagittal crest) based on PIN 4659/1 (Fig. 2B, D).

\section{Morphology of the marginal dentition (76)}

As for the Tsuji (2006) analysis, this character is modified so that state one is "two cusps' and state two is "leaf shaped teeth with several denticles'. Scoring for the pareiasaur Bradysaurus was changed to '2' and Procolophon was scored as ' 1 ' (see discussion for this scoring in section 4.1).

\section{Fossa meckelii length (79)}

As for the Tsuji (2006) analysis, this character is modified so that a long one is 'more than $30 \%$ ' and a short fossa meckelii is 'less than $25 \%$ ' of the length of the lower jaw. Scoring for Procolophon was changed to ' 1 ' (short) (see discussion for this scoring in section 4.1).

\section{Accessory lateral shelf on surangular (81)}

Scoring for Nyctiphruretus was changed to ' 1 ' (shelf present) based on PIN 4660/18 (Fig. 4b).

\section{Olecranon process (112)}

Scoring for the olecranon process of the ulna is changed to ' 1 ' (small or absent) for Nyctiphruretus as it appears to 
A

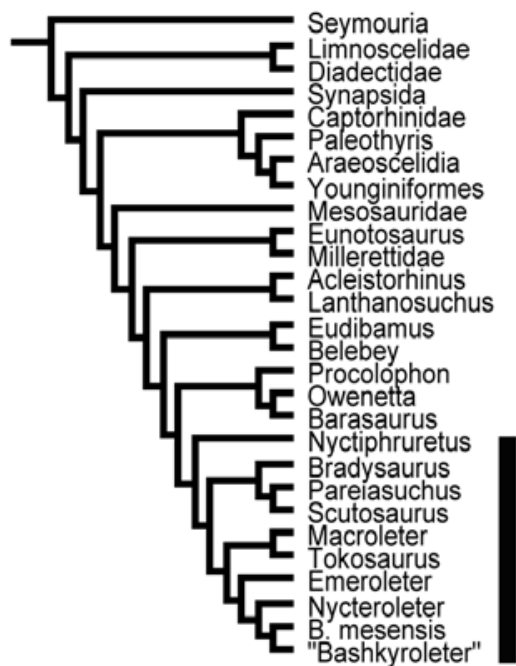

C

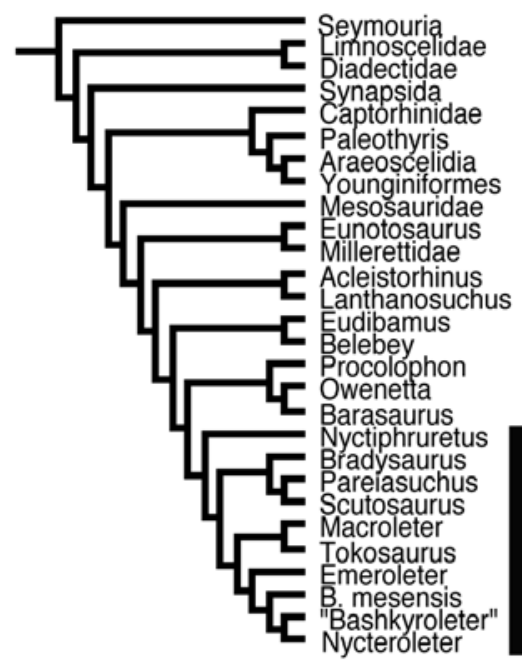

E

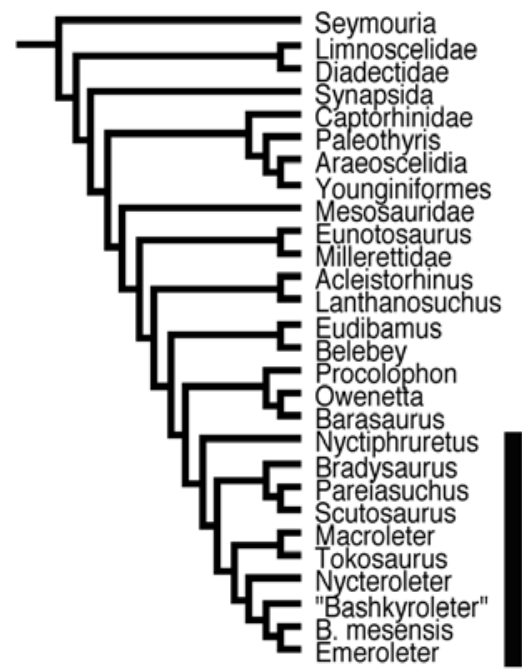

B

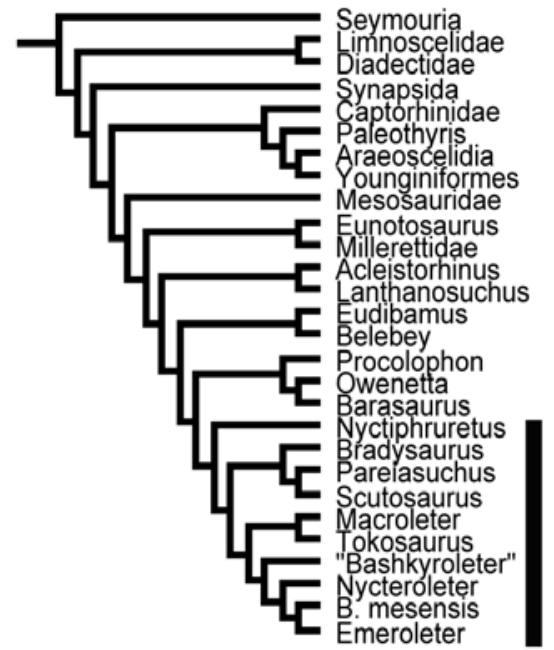

D

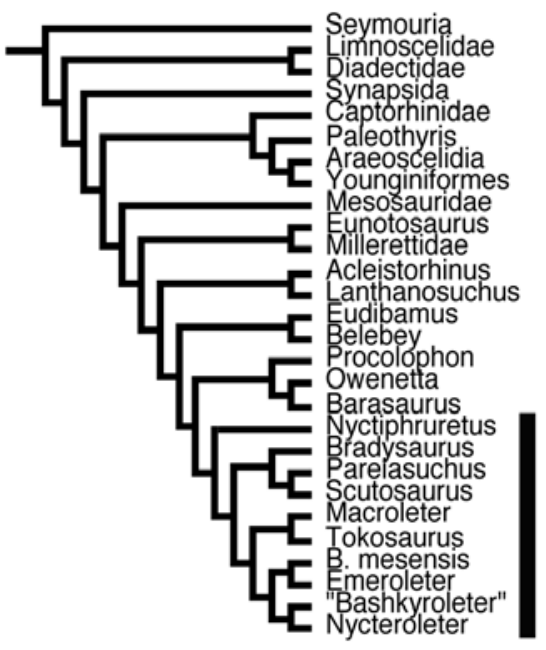

$\mathbf{F}$

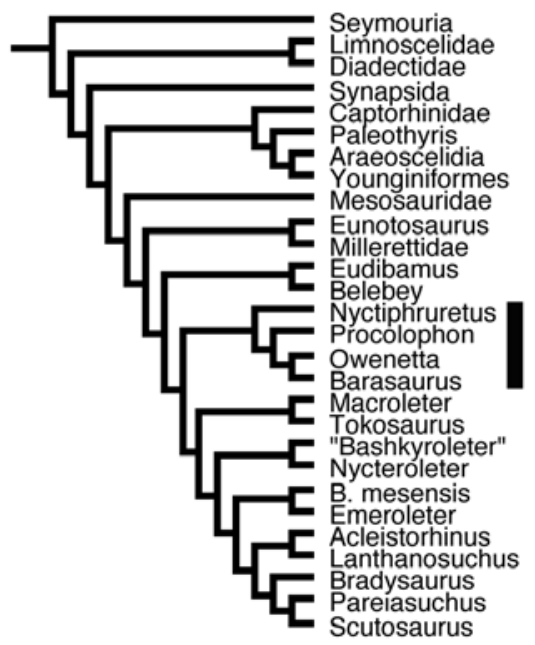

Fig. 8.- The six MPTs from an analysis of parareptilian interrelationships, Müller and Tsuji (2007) data matrix rescored. Nyctiphruretus and its sister group are indicated with a black vertical bar in each tree, and a clade formed by lanthanosuchoids and pareiasaurs is indicated with a gray vertical bar in $8 \mathrm{~F}$.

Fig. 8.- Los seis MPTs resultantes del análisis de las interrelaciones de parareptiles, basado en la matriz recodificada de. Müller y Tsuji (2007). Nyctiphruretus y su grupo hermano se indican con una barra vertical en negro en cada uno de los árboles, un clado formado por lanthanosuchoides y pareiasurios se indican con una barra gris vertical en $8 \mathrm{~F}$. 
A

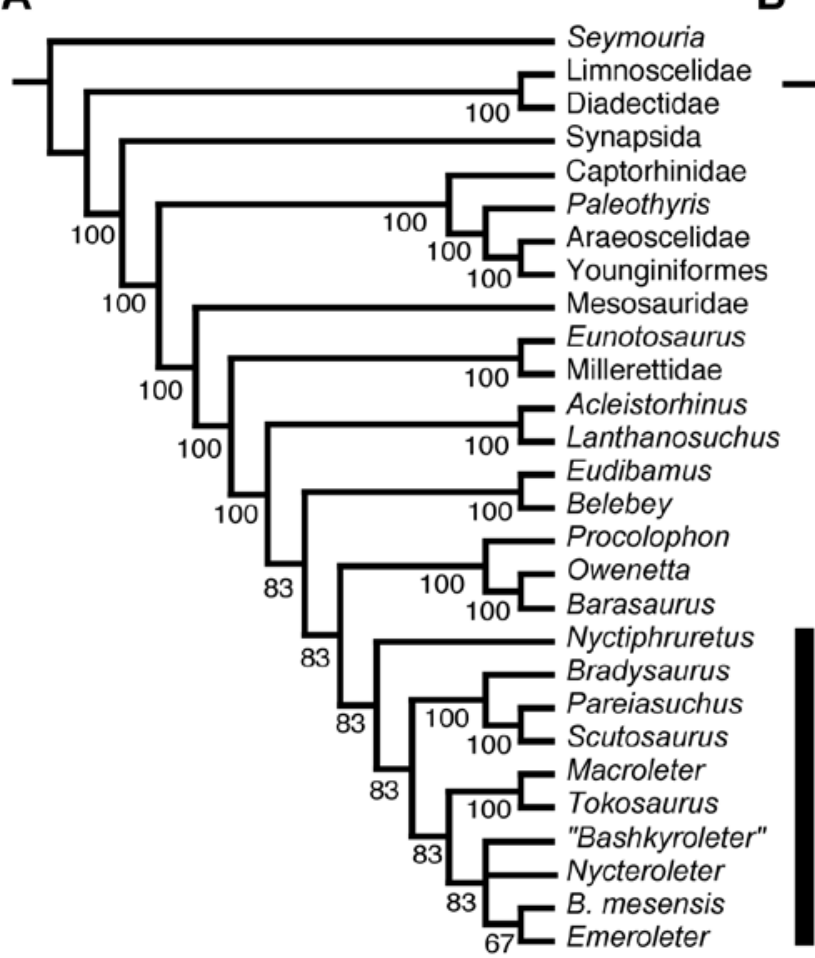

B

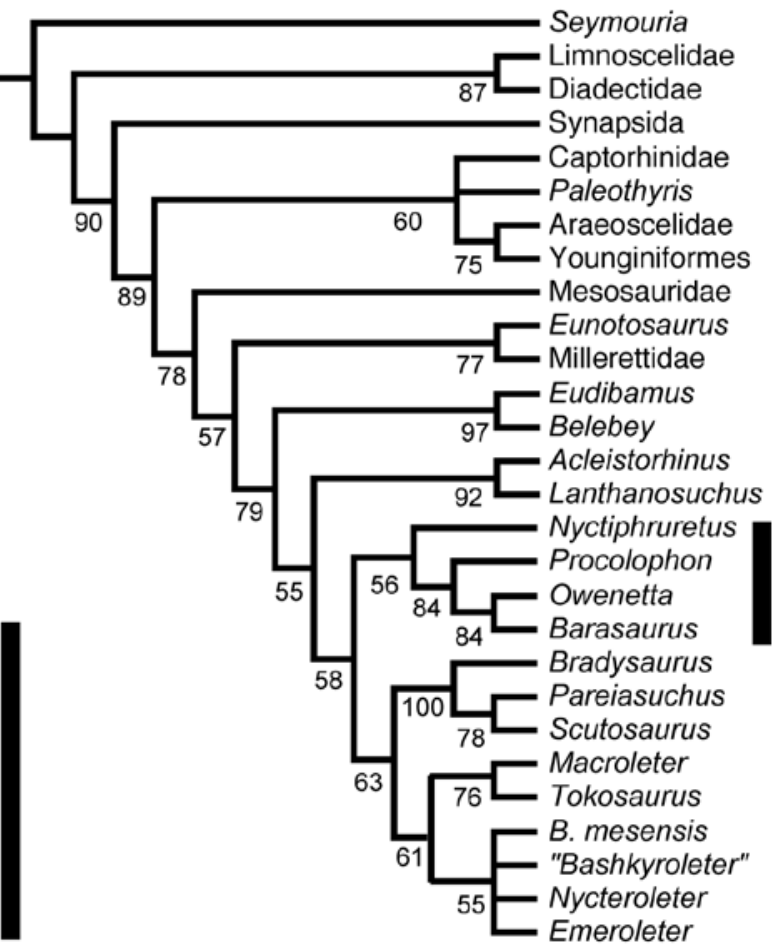

Fig. 9.- A, 50\% majority consensus tree, and B, 50\% bootstrap consensus tree from an analysis of parareptilian interrelationships, Müller and Tsuji (2007) data matrix rescored. In A, values below the nodes indicate the proportion of MPTs where the clade is present; in B, the values indicate bootstrap frequencies. Nyctiphruretus and its sister group are indicated with a black vertical bar in both trees.

Fig. 9.- A, árbol consenso de la mayoría 50\%, y B, consenso 50\% bootstrap de las relaciones de parentesco de parareptiles, basado en la matriz de datos de Müller y Tsuji (2007) recodificada. En A, los valores debajo de los nodos indican la proporciones de MPTs donde el clado está presente; en B, los valores indican frecuencias de bootstrap. Nyctiphruretus y su grupo hermano se indican con una barra negra vertical en ambos árboles.

protrude very little in PIN 158/4 and PIN 162 (pers. obs).

\section{Oblique ventral ridge of femur (117)}

Scoring for this character was changed to ' 0 ' (present) for Nyctiphruretus as it appears to be present on the femur of PIN 162 (pers. obs.).

\section{Temporal notch present or absent (134)}

A deep, laterally exposed posterior temporal emargination, or a temporal notch, formed by the quadratojugal and the squamosal, is present in Macroleter, Bashkyroleter, Emeroleter, Nycteroleter ineptus, and Tokosaurus. Müller and Tsuji (2007) interpreted this structure as hosting the tympanum in these taxa. However, Nyctiphruretus (Fig. 2C-D) and the procolophonoids also have a posterior temporal emargination, formed by the quadratojugal and the squamosal, with a small contribution from the quadrate ventrally. In Procolophon, and many other procolophonids, this emargination is only visible occipitally because of the posterolateral expansion of the quadratojugal but in owenettids and Nyctiphruretus it is laterally exposed. Müller and Tsuji (2007) correctly identified this structure to be present in the procolophonoids but not in Nyctiphruretus. Thus, scoring for Nyctiphruretus was changed to ' 0 ' (notch present).

The modified data set was analysed using the heuristic search option (random stepwise addition, multistate taxa interpreted as polymorphism, 1000 replicates) with both ACCTRAN and DELTRAN optimization in PAUP* 4.0b10 (Swofford, 2002). Characters were left unweighted and unordered. These are the same settings used in the analysis of Müller and Tsuji (2006). Bootstrap analysis (1000 replicates) and decay analysis were performed using PAUP* 4.0b10 and TreeRot 2.0 (Sorenson, 1999). MacClade 4.06 (Maddison and Maddison, 2003) was used for modifying the original data set and for identifying synapomorphies.

\section{Results and discussion}

Six MPTs were found, with a tree length of 387 . The consistency index for these trees was 0.442 , the retention index 0.703 , the homoplasy index 0.558 , and the rescaled 


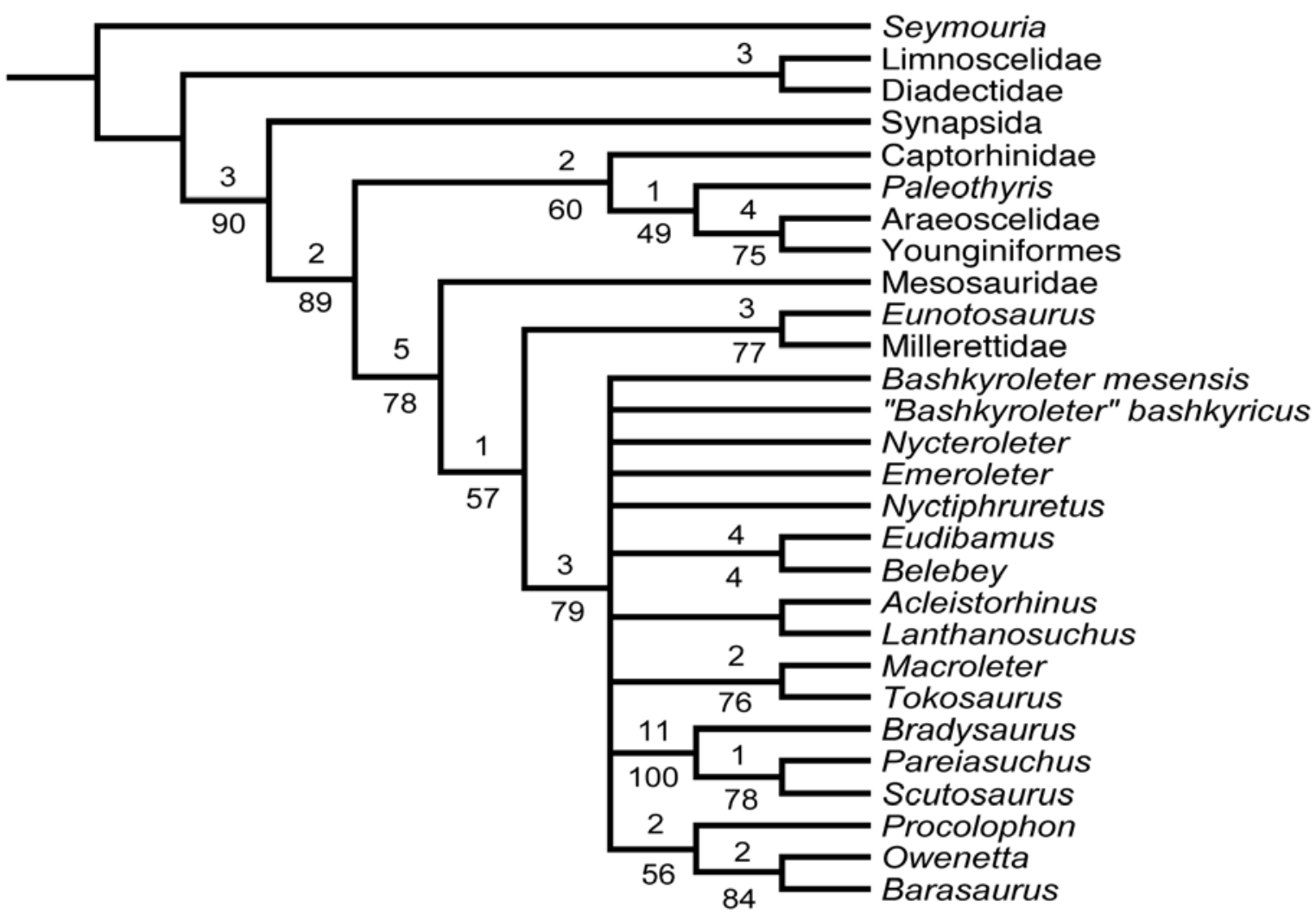

Fig. 10.- Strict consensus of the six MPTs recovered in an analysis of parareptilian interrelationships, Müller and Tsuji (2007) data matrix rescored. Bootstrap frequencies are indicated below and decay values above each node.

Fig 10.- Consenso estricto de seis MPTs resultantes de las relaciones de parentesco de parareptiles, matriz de datos basada en Müller y Tsuji (2007) y recodificada. Las frecuencias de bootstrap se indican debajo y los valores de decaimiento encima de los nodos.

consistency index 0.311 . The six MPTs are shown in Figure 8 , a $50 \%$ majority rule consensus of those trees in Figure 9A, and a 50\% majority bootstrap tree in Figure 9B. In addition, a strict consensus of the six MPTs, along with decay and bootstrap values, is shown in Figure 10. The reason the $50 \%$ bootstrap tree is presented on its own here (Fig. 9B) is because it shows support for clades not present in the $50 \%$ majority rule consensus tree (Fig. 9A) or the strict consensus tree (Fig. 10). It is also acknowledged that while bootsrapping is a commonly used method of assessing confidence in phylogenetic analysis, it is also is a controversial method. The results of a bootstrap analysis can be interpreted to represent the probability of a phylogenetic result representing the true phylogeny or the repeatability of a given result (Felsenstein, 1985; Hillis and Bull, 1993), although the former view is rather over-optimistic and the latter is only true if the dataset is entirely unbiased. The level of confidence in the accuracy of bootstrap results also varies from the very strict view of Felsenstein (1985), where only nodes with support of over $95 \%$ are considered significant, to those who consider levels between $50 \%$ and $70 \%$ well or at least moderately supported (La Farge et al., 2002, Marvaldi et al.,
2002). It is also true that any grouping that is included in a 50\% majority consensus bootstrap tree (obtained from adequate number of repetitions) can be considered to have some level of support, as this is more than would be expected from random source data (Sanderson and Wojciechowski, 2000; Zander, 2007).

As the scoring for only Nyctiphruretus and the procolophonoids were modified, the overall topology of the resulting trees is consistent with the results of Müller and Tsuji (2007), except for one tree where the Lanthanosuchoidea (Lanthanosuchus and Acleistorhinus) were positioned as the sister group of the pareiasaurs (Fig. 8F). This tree is also the only MPT where Nyctiphruretus has a sister-group relationship with the Procolophonoidea (Fig. 8F). In all other MPTs (Fig. 8A-D) and the $50 \%$ majority consensus tree (Fig. 9A), Nyctiphruretus is recovered as the sister taxon to the clade consisting of the other nonpareiasaurian Mezen river parareptiles and pareiasaurs. However, this grouping only received $19 \%$ bootstrap support, whereas the Nyctiphruretus-Procolophonoidea clade was recovered in the $50 \%$ majority bootstrap tree with 56\% support (Fig. 9B). Also, the position of Belebey and Eudibamus (Bolosauridae) as the sister group of 
the clade consisting of procolophonoids, pareiasaurs and the non-pareiasaurian Mezen River parareptiles (including Nyctiphruretus), which was recovered in five of the MPTs (Fig. 8A-D) and the 50\% majority consensus tree (Fig. 9A), only received 30\% bootstrap support, whereas the Lanthanosuchoidea took over this position in the $50 \%$ majority bootstrap tree with 55\% support (Fig. 9B). Because of the one MPT where the Lanthanosuchoidea-Pareiasauria and Nyctiphruretus-Procolophonoidea clades were recovered (Fig. 8F), the strict consensus of the six MPTs resulted in polytomy consisting of the lanthanosuchoids, the bolosaurids, the pareiasaurs, the procolophonoids, and the non-pareiasaurs Mezen River parareptiles (Fig. 10). This clade has a decay value of 3 but values for the nodes between these groups (found in the separate 6 MPTs) are 0 because of the polytomy.

Nevertheless, as the main focus here is the phylogenetic relationships of Nyctiphruretus, the sister-group relationship of Nyctiphruretus with the clade consisting of the other non-pareiasaurian Mezen river parareptiles and pareiasaurs, found in five of the six MPTs, is diagnosed by the following four synapomorphies: median postparietal (5:0, unambiguous), choana curved posteromedially; palatine forms its posterior and part of lateral edge (42:1), alar flange of the vomer present (43:1), and transverse processes or ribs present on at least thirteen caudals (98:1). However, also the Nyctiphruretus-procolophonoid clade that was recovered in the one of the six MPTs (and the 50\% majority bootstrap tree), is diagnosed by four synapomorphies: narial shelf present (1:1); ventral temporal emargination present and open ventrally (29:2); posterior margin of skull roof slightly concave with protruding medial postparietal(s) (40:3), and ventral surface of the pleurocentra bearing an excavation on either side of the midline (95:1). As with the original and rescored Tsuji (2006) analysis, the results of the rescored data matrix of Müller and Tsuji (2007) indicate that the clade including pareiasaurs, procolophonoids, and all the Mezen River parareptiles, including Nyctiphruretus and Macroleter, is moderately well supported (Figs 8, 9) but the exact position of Nyctiphruretus within that clade remains inconclusive.

\section{Discussion and conclusions}

New information on the cranial structure of Nyctiphruretus has confirmed that Nyctiphruretus is closely related to procolophonoids, pareiasaurs and the other non-pareiasaurian Mezen river parareptiles but the interrelationships within this clade remain unresolved. The hypothesis that Nyctiphruretus and procolophonoids form a clade called Procolophonomorpha (Bulanov 2002; Ivakhnenko 1979,
1987, 1990; Tverdokhlebova and Ivakhnenko, 1994) was supported by the results of a reanalysis of the Tsuji (2006) data matrix, whereas the results of a reanalysis of the Müller and Tsuji (2007) data matrix were inconclusive, supporting either the 'Procolophonomorpha hypothesis' or the results of the original Tsuji (2006) analysis, where Nyctiphruretus formed a sister-group relationship with a clade consisting of pareiasaurs and Macroleter (and other non-pareiasaurian Mezen River parareptiles in Müller and Tsuji, 2007). Both scenarios are plausible because Nyctiphruretus shares several synapomorphies with both of its proposed sister groups. One of these is the presence of a maxillary depression, or a narial shelf, behind the external naris. It is found in all procolophonoids (except in some derived leptopleuronines) and has been used as one of the characters defining Procolophonoidea (Cisneros, 2008b,c; Lee, 1995; Modesto and Damiani, 2007; Säilä, 2008). Now it is also recognized to be present in Nyctiphruretus, although the depression is much deeper, and continues on the anterodorsal side of the naris, which is different from the condition seen in procolophonoids. Until the phylogenetic position of Nyctiphruretus is fully resolved, however, the conditions shared by Nyctiphruretus and the other taxa are considered as possible synapomorphies of the hypothetical clades they represent.

In conclusion, Nyctiphruretus does not fall within the Procolophonoidea, but it is possible it is a sister group of the clade. However, because the sister-group relationship is uncertain, Nyctiphruretus cannot be included among the procolophonoid lineages originating, and in this case disappearing, during the Permian and cannot be used to estimate the P-Tr extinction survival rates of Procolophonoidea.

Furthermore, the phylogenetic position of Nyctiphruretus is only one of the problems that have arisen in the recent efforts of resolving the interrelationships of the 'Parareptilia' (Laurin and Reisz, 1995; Lee, 1995; Modesto, 1999, 2006; Modesto and Reisz, 2008; Reisz et al., 2007). The number of taxa included into the analyses has increased with more detailed descriptions of several taxa becoming available, and while this should increase the accuracy of the character coding in the analyses, it also increases the number of possible topologies exponentially and can create problems with the computer programs used to find the most optimal solutions (Felsenstein 1978; Prendini 2001). Additionally, the problem of limited information about the cranial anatomy of taxa like Colobomycter (Modesto and Reisz, 2008) and the postcranial anatomy of the majority of the taxa that affect the resolution of the analyses, also remain until additional specimens are discovered or descriptions of existing, but undescribed, specimens are published. 


\section{Acknowledgements}

I thank my $\mathrm{PhD}$ project supervisors Michael J. Benton and Sean P. Modesto for their help and advice, and the Osk. Huttunen Foundation for funding my Ph.D. project. I am grateful to Valery Bulanov (PIN) for access to Nyctiphruretus specimens, and to Sandra Chapman (BMNH), and Sheena Kaal (SAM) for access to procolophonoid specimens. Johannes Müller and Linda Tsuji kindly provided additional information concerning the phylogenetic studies I reanalysed in this paper. My visit to PIN was funded by the Society of Vertebrate Paleontology R. Estes Memorial Grant, the University of Bristol Earth Sciences Bob Savage Memorial Grant, and by a Discovery Grant (no. 288126-04) from the Natural Sciences and Engineering Research Council (NSERC) of Canada (to S. P. Modesto). I thank Michel Laurin for his review of the manuscript. Special thanks also to Ian J. Corfe for helpful advice and discussion on the manuscript, and to the Jernvall Evo-Devo research group for the support I received during the final stages of my $\mathrm{PhD}$ thesis project.

\section{References}

Benton, M. J., Twitchett, R. J. (2003): How to kill (almost) all life: the end-Permian extinction event. TRENDS in Ecology and Evolution, 18: 358-365. http://dx.doi.org/10.1016/S01695347(03)00093-4

Benton, M.J., Tverdokhlebov, V.P., Surkov, M.V. (2004). Ecosystem remodelling among vertebrates at the Permian-Triassic boundary in Russia. Nature 432: 97-100. http://dx.doi. org/10.1038/nature02950

Berman D. S., Reisz, R. R., Bolt, J. R., Scott, D. (1995). The cranial anatomy and relationships of the synapsid Varanosaurus (Eupelycosauria: Ophiacodontidae) from the Early Permian of Texas and Oklahoma. Annals of Carnegie Museum, 64: 99-133.

Brinkman, D. (1988): Size-independent criteria for estimating relative age of Ophiacodon and Dimetrodon (Reptilia, Pelycosauria) from the Admiral and Lower Belle Plains formations of West Central Texas. Journal of Vertebrate Paleontology, 8: 172-180. http://dx.doi.org/10.1080/02724634.1988.10011695

Bulanov, V. V. (2002): New data on procolophons from the Permian of Eastern Europe. Paleontological Journal, 36: 525-530.

Bulanov, V. V. (2003): Evolution and systematics of seymouriamorph parareptiles. Paleontological Journal, 37: S1-105.

Carroll, R. L., Lindsay, W. (1985): Cranial anatomy of the primitive reptile Procolophon. Canadian Journal of Earth Sciences, 22: $1571-1587$.

Chudinov, P. K. (1957): Cotylosaurs from the Upper Permian redbeds deposits of the Preurals. Trudy Paleontologicheskogo Instituta, Academiia Nauca SSSR, 68: 19-87.

Cisneros, J. C. (2008a): Taxonomic status of the reptile genus Procolophon from the Gondwanan Triassic. Palaeontologia Africana, 43: 7-17.

Cisneros, J. C. (2008b): New basal procolophonid reptile from the Katberg Formation (Lower Triassic) of the South African Karoo.
Palaeoworld, 17: 126-134. http://dx.doi.org/10.1016/j.palwor.2008.06.003

Cisneros, J. C. (2008c): Phylogenetic relationships of procolophonid parareptiles with remarks on their geological record. Journal of Systematic Palaeontology, 6: 345-366. http://dx.doi. org/10.1017/S1477201907002350

Cisneros, J. C., Schultz, C. L. (2003): Soturnia caliodon n. g. n. sp., a new procolophonid reptile from the Upper Triassic of Southern Brazil. Neues Jahrbuch für Geologie und Paläontologie, Abhandlungen 227: 365-380.

Clark, J., Carroll, R. L. (1973): Romeriid reptiles from the Lower Permian. Harvard Museum of Comparative Zoology, Bulletin, 144: 353-407.

Cox, C. B. (1969): The problematic Permian reptile Eunotosaurus. Bulletin of the British Museum of Natural History (Geology), 18: 167-198.

deBraga, M. (2003): The postcranial skeleton, phylogenetic position, and probable lifestyle of the Early Triassic reptile Procolophon trigoniceps. Canadian Journal of Earth Sciences 40: 527-556. http://dx.doi.org/10.1139/e02-082

deBraga, M., Reisz, R. R. (1996): The early Permian reptile Acleistorhinus pteroticus and its phylogenetic position. Journal of Vertebrate Paleontology, 16: 384-395. http://dx.doi.org/10. 1080/02724634.1996.10011328

deBraga, M, Rieppel, O. (1997): Reptile phylogeny and the interrelationships of turtles. Zoological Journal of the Linnean Society, 120: 281-354. http://dx.doi.org/10.1111/j.1096-3642.1997. tb01280.x

Dilkes, D. W., Reisz, R. R. (1996): First record of a basal synapsid ("mammal-like reptile") in Gondwana. Proceedings of the Royal Society of London, B series, 263: 1165-1170. http://dx.doi. org/10.1098/rspb.1996.0170

Efremov, J. A. (1938): Some new Permian reptiles of the U.S.S.R. Comptes Rendus (Doklady), 19: 771-776.

Efremov, J. A. (1940): Die Mezen-Fauna der permischen reptilien. Neues Jahrbuch für Minerologie, Geologie und Paläontologie, Abhandlungen B, 84: 379-466.

Felsenstein, J. (1978): The number of evolutionary trees. Systematic Zoology, 27: 27-33. http://dx.doi.org/10.2307/2412810

Felsenstein, J. (1985): Confidence limits on phylogenies: an approach using the bootstrap. Evolution, 39: 783-791. http:// dx.doi.org/10.2307/2408678

Gauthier, J. A. (1994): The diversification of the amniotes. In: D. E. Prothero, R. M. Schoch (eds.), Major features of vertebrate evolution - Geological Society of America Meeting. Paleontological Society, Knoxville: 129-159.

Gow, C. E. (1972): The osteology and relationships of Millerettidae (Reptilia: Cotylosauria). Journal of Zoology, London 167: 219264. http://dx.doi.org/10.1111/j.1469-7998.1972.tb01731.x

Gow, C. E. (1997): A reassessment of Eunotosaurus africanus Seeley (Amniota: Parareptilia). Palaeontologia Africana, 33: 33-42.

Gow, C. E. (2000): A new procolophonid (Parareptilia) from the Lystrosaurus Assemblage Zone, Beaufort Group, South Africa. Palaeontologia Africana, 36: 21-23.

Griswold, C. E., Coddington, J. A., Hormiga, G., and Scherff, N. (1998): Phylogeny of the orb-web building spiders (Araneae, Orbiculariae: Deinopoidea, Arenoidea). Zoological Journal of the Linnean Society, 123: 1-99. http://dx.doi.org/10.1006/ zjls.1997.0125 
Hillis, D. M., Bull, J. J. (1993): An empirical test of bootstrapping as a method for assessing confidence in phylogenetic analysis. Systematic Biology, 42: 182-192. http://dx.doi.org/10.1093/ sysbio/42.2.182

Ivakhnenko, M. F. (1979): Permian and Triassic procolophonids of the Russian platform. Trudy Paleontologicheskogo Instituta, Academiia Nauka SSSR, 164:1-80. [In Russian]

Ivakhnenko, M. F. (1983): New procolophonids from Eastern Europe. Paleontological Journal, 17: 135-139.

Ivakhnenko, M. F. (1987): Permian parareptiles of the USSR. Trudy Paleontologicheskogo Instituta, Akademiia Nauka SSSR, 233: 1-159. [In Russian].

Ivakhnenko, M. F. (1990): A late Paleozoic faunal assemblage of tetrapods from the deposits of the Mezen River Basin. Paleontological Journal, 4: 81-90.

Ivakhnenko, M. F. (1997): New Late Permian nycteroleterids from Eastern Europe. Paleontological Journal, 31: 552-558.

Ketchum, H. F., Barrett, P. M. (2004): New reptile material from the Lower Triassic of Madagascar: implications for the Permian-Triassic extinction event. Canadian Journal of Earth Sciences, 41: 1-8. http://dx.doi.org/10.1139/e03-084

Kron, K. A. and Judd, W. S. (1997): Systematics of the Lyonia Group (Antomedeae, Ericaceae) and the use of species of terminals in higher-level cladistic analyses. Systematic Botany, 22: 479-492. http://dx.doi.org/10.2307/2419822

La Farge, C., Shaw, A. J., Vitt, D. H. (2002): The circumscription of the Dicranaceae (Bryopsida) based on the chloroplast regions trL-trnF and rps4. Systematic Botany, 27: 435-452.

Langston, W. (1965): Oedalops campi (Reptilia: Pelycosauria) new genus and species from the Lower Permian of New Mexico, and the family Eothyrididae. Bulletin of the Texas Memorial Museum, 9: 1-47.

Laurin, M., Reisz, R. R. (1995): A reevaluation of early amniote phylogeny. Zoological Journal of the Linnean Society, 113:165223. http://dx.doi.org/10.1006/zjls.1995.0007

Lee, M. S. Y. (1993): The origin of the turtle body plan: bridging a famous morphological gap. Science, 261: 1716-1720. http:// dx.doi.org/10.1126/science.261.5129.1716

Lee, M. S. Y. (1995): Historical burden of systematics and interrelationships of 'parareptiles'. Biological Reviews, 70: 459-547. http://dx.doi.org/10.1111/j.1469-185X.1995.tb01197.x

Lee, M. S. Y. (1997): Pareiasaur phylogeny and the origin of turtles. Zoological Journal of the Linnean Society, 120: 197-280. http://dx.doi.org/10.1006/zjls.1997.0080

Lee, M. S. Y. (2000): The Russian pareiasaurs. In: M. J. Benton, M. A. Shishkin, D. M. Unwin (eds.), The age of dinosaurs in Russia and Mongolia. Cambridge University Press, Cambridge: 71-85.

Maddison, W. P., Maddison, D. R. (2003): MacClade: Analysis of phylogeny and character evolution, version 4.06. Sinauer Association, Sunderland, Massachusetts.

Marvaldi, A. E., Sequeira, A. S., O’Brien, C. W., Farrell, B. D. (2002): Molecular and morphological phylogenetics of weevils (Coleoptera, Curculionoidea): do niche shifts accompany diversification? Systematic Biology, 51: 761-785. http://dx.doi. org/10.1080/10635150290102465

Modesto, S. P. (1999): Observations on the structure of the Early Permian reptile Stereosternum tumidum Cope. Palaeontologia Africana, 35: 7-19.
Modesto, S. P. (2006): The cranial skeleton of the Early Permian aquatic reptile Mesosaurus tenuidens: implications for relationships and palaeobiology. Zoological Journal of the Linnean Society, 146: 345-368. http://dx.doi.org/10.1111/j.10963642.2006.00205.x

Modesto, S. P., Damiani, R. J. (2003): Taxonomic status of Thelegnathus browni Broom, a procolophonid reptile from the South African Triassic. Annals of Carnegie Museum, 72: 53-64.

Modesto, S. P., Damiani, R. J. (2007): The procolophonoid reptile Sauropareion anoplus from the lowermost Triassic of South Africa. Journal of Vertebrate Paleontology, 27: 337-349. http:// dx.doi.org/10.1671/0272-4634(2007)27[337:TPRSAF]2.0. $\mathrm{CO} ; 2$

Modesto, S. P., Reisz, R. R. (2008): New material of Colobomycter pholeter, a small parareptile from the Lower Permian of Oklahoma. Journal of Vertebrate Paleontology, 28: 677-684. http://dx.doi.org/10.1671/0272-4634(2008)28[677:NMOCPA]2 $0 . \mathrm{CO} ; 2$

Modesto, S., Sues, H.-D., Damiani, R. (2001): A new Triassic procolophonoid reptile and its implications for procolophonoid survivorship during the Permo-Triassic extinction event. Proceedings of the Royal SocietyofLondon, Biological Series, 268:2047-2052. http://dx.doi.org/10.1098/rspb.2001.1766

Modesto, S. P., Damiani, R. J., Neveling, J., Yates, A. M. (2003): A new Triassic owenettid parareptile and the Mother of Mass Extinctions. Journal of Vertebrate Paleontology, 23: 715-719. http://dx.doi.org/10.1671/1962

Müller, J., Reisz, R. R. (2005): An early captorhinid reptile (Amniota, Eureptilia) from the Upper Carboniferous of Hamilton, Kansas. Journal of Vertebrate Paleontology, 25: 561-568. http://dx.doi.org/10.1671/0272-4634(2005)025[0561:AECR $\mathrm{AE}] 2.0 . \mathrm{CO} ; 2$

Müller, J., Tsuji, L. A. (2007): Impedance-matching hearing in Paleozoic reptiles: evidence of advanced sensory perception at an early stage of amniote evolution. Plos One, 9: 1-7.

Novikov, I.V., Sues, H.-D. (2004): Cranial osteology of Kapes (Parareptilia: Procolophonidae) from the Lower Triassic of Orenburg Province, Russia. Neues Jahrbuch für Geologie und Paläontologi, Abhandlungen, 232: 267-281.

Piñeiro, G., Rojas, A., Ubilla, M. (2004): A new procolophonoid (Reptilia, Parareptilia) from the Upper Permian of Uruguay. Journal of Vertebrate Paleontology, 24: 814-821. http://dx.doi. org/10.1671/0272-4634(2004)024[0814:ANPRPF]2.0.CO;2

Prendini, L. (2001): Species or supraspesific taxa as terminals in cladistic analysis? Groundplans versus exemplars revisited. Systematic Biology, 50: 290-300. http://dx.doi. org/10.1080/10635150151125950

Reisz, R. R. (2005): Oromycter, a new caseid from the Lower Permian of Oklahoma. Journal of Vertebrate Paleontology, 25: 905-910. http://dx.doi.org/10.1671/02724634(2005)025[0905:OANCFT]2.0.CO;2

Reisz, R. R., Laurin, M. (1991): Owenetta and the origin of turtles. Nature, 349: 324-326. http://dx.doi.org/10.1038/349324a0

Reisz, R. R., Laurin, M. (2004).: A reevaluation of the enigmatic Permian synapsid Watongia and its stratigraphic significance. Canadian Journal of Earth Sciences, 41: 377-346. http:// dx.doi.org/10.1139/e04-016

Reisz, R. R., Scott, D. M. (2002): Owenetta kitchingorum, n. sp., a small parareptile from the Lower Triassic of South Africa. 
Journal of Vertebrate Paleontology, 22: 244-256. http://dx.doi. org/10.1671/0272-4634(2002)022[0244:OKSNAS]2.0.CO;2

Reisz, R. R., Müller, J.,Tsuji, L., Scott, D. (2007): The cranial osteology of Belebey vegrandis (Parareptilia: Bolosauridae), from the Middle Permian of Russia, and its bearing on the reptilian evolution. Zoological Journal of the Linnean Society, 151: 191214. http://dx.doi.org/10.1111/j.1096-3642.2007.00312.x

Romer, A. S., Price, L. I. (1940): Review of the Pelycosauria. Geological Society of America, Special Papers 28. Arno Press, New York: $538 \mathrm{p}$.

Säilä, L. K. (2008): The osteology and affinities of Anomoiodon liliensterni, a procolophonid reptile from the Lower Triassic Buntsandstein of Germany. Journal of Vertebrate Paleontology, 28: 11991205. http://dx.doi.org/10.1671/0272-4634-28.4.1199

Säilä, L. K. (2009): Alpha taxonomy of the Russian Permian procolophonoid reptiles. Acta Palaeontologica Polonica, 54: 599608. http://dx.doi.org/10.4202/app.2009.0017

Sanderson, M. J., Wojciechowski, M. F. (2000): Improved bootstrap confidence limits in large-scale phylogenies, with an example from neo-Astragalus (Lugaminosae). Systematic Biology, 49: 671-685.

Sorenson, M. D. (1999): TreeRot, version 2. Boston University, Boston, Massachusetts.

Spencer, P. S., Benton, M. J. (2000): Procolophonoids from the Permo-Triassic of Russia. In: M. J. Benton, M. A. Shishkin, D. M. Unwin, E. N. Kurochkin (eds.), The Age of Dinosaurs in Russia and Mongolia. Cambridge University Press, Cambridge: 160-176. Swofford, D. L. (2002): PAUP*: Phylogenetic Analysis Using Parsimony (*and other methods). Version 4.0b10. Sinauer Associates, Sunderland, Massachusetts.

Templeton, A. R. (1983): Phylogenetic inference from restriction endonuclease cleavage site maps with particular reference to the evolution of humans and the apes. Evolution, 37: 221-244. http://dx.doi.org/10.2307/2408332

Tsuji, L. A. (2006): Cranial anatomy and phylogenetic affinities of Permian parareptile Macroleter poezicus. Journal of Vertebrate Paleontology, 26: 849-865. http://dx.doi.org/10.1671/02724634(2006)26[849:CAAPAO]2.0.CO;2

Tverdokhlebova, G. I., Ivakhnenko, M. F. (1994): New tetrapods from the Tatarian of Eastern Europe. Paleontological Journal, 28: $153-159$.

Wiens, J. J. (1998): The accuracy of methods for coding and sampling higher-level taxa for phylogenetic analysis: A simulation study. Systematic Biology, 47: 397-413. http://dx.doi. org/10.1080/106351598260789

Yeates, D. K. (1995): Groundplans and exemplars: Paths to the tree of life. Cladistics 11:343-357. http://dx.doi.org/10.1016/07483007(95)90020-9

Zander, R.H. (2007): Nine easy steps for constructing reliable trees for published phylogenetic analyses. Annals of the Missouri Botanical Gardens, 94: 690-708.

\section{Appendix 1}

The rescored data matrix of Tsuji (2006) used for estimating the phylogenetic position of Nyctiphruretus. Polymorphism is indicated with by letters, $\mathrm{A}=0 \& 1, \mathrm{~B}=1 \& 2, \mathrm{C}=0 \& 2, \mathrm{D}=0 \& 1 \& 2$.

Synapsida

A0 OB $00000000000000000 A A 00000010 A 00 A 000000 C 00000000010000000 A 00 A 000000000 C 0000$ DO OAAO000000 Mesosauridae $0000000000 ? 0 ? 00010000001110000 ? ? 011000001000001 ? 000102 ? ? ? 0001000004 ? 1 ? 000 ? 000 ? ? 1001 ? 1000 ?$ Eunotosaurus

?00000?????0100110?1?011111100??20?12010120??????001?????0010000104????0???10???0???0??0? Millerettidae

00000010002010001000101 A10110A0A201120101200000000010110100110100040110000010?00001000000 Eudibamus

000 ???2100?0011??2100?01110?021101?01?00201?????1122111??0001?0??0????11????02?????200?20 Belebey

000120210020011 ?0210010111000211010001002010010?112211110000100??04??0???00?020110120?021 Acleistorhinus

001210???1?001011011111001010111301020101200000100011011111?1010012??01100100???1011010?1 Lanthanosuchus

001C201001?0010?1011?0111121111130101020120001010001101101111010012?0?11?11?0??????????? Macroleter

0002A0210121010010111100103111112000212110111101000111?011001101101?1?0001??02?111111??11 Nyctiphruretus

1001112101?0010?10111?01103100??2020212032111101101111111001110110101100001?0???111?11001

Bradysaurus

$0102111000 ? 1010 ? 20111001102110 ? ? 3000202111111101 ? 0111110110111011011100001102$ ?1110111?110

Scutosaurus

0102111000 ?1010110111101102110??3000202110111101?011111111011101101110000111221110111?110

Procolophon

10022?211121010?20111?01103100??20202100C010010110121111100101011020110010111211111111011 Owenetta

1002012111?10?0?20111?00103100??20202100321001011012111110011101103?1?00100?0211101111011 Barasaurus

100201?110?0010?20111?01103100??20202100321001011012?11110011101103?1?00100?0??????????? Captorhinidae

000C00100011011?21000010010000??0010003002000010000002??100110A0204?100000000100001000000 
